\title{
Directed Assembly of Particles for Additive Manufacturing of Particle-Polymer Composites
}

\author{
Soheila Shabaniverki ${ }^{1}$ and Jaime J. Juárez ${ }^{1,2, *(D)}$ \\ 1 Department of Mechanical Engineering, Iowa State University, Ames, IA 50011, USA; soheilas@iastate.edu \\ 2 Center for Multiphase Flow Research and Education, Iowa State University, Ames, IA 50011, USA \\ * Correspondence: jjuarez@iastate.edu; Tel.: +1-515-294-3298
}

Citation: Shabaniverki, S.; Juárez, J.J. Directed Assembly of Particles for Additive Manufacturing of Particle-Polymer Composites. Micromachines 2021, 12, 935. https://doi.org/10.3390/mi12080935

Academic Editor: Matteo Cocuzza

Received: 21 July 2021

Accepted: 3 August 2021

Published: 7 August 2021

Publisher's Note: MDPI stays neutral with regard to jurisdictional claims in published maps and institutional affiliations.

Copyright: (c) 2021 by the authors. Licensee MDPI, Basel, Switzerland. This article is an open access article distributed under the terms and conditions of the Creative Commons Attribution (CC BY) license (https:/ / creativecommons.org/licenses/by/ $4.0 /)$.

\begin{abstract}
Particle-polymer dispersions are ubiquitous in additive manufacturing (AM), where they are used as inks to create composite materials with applications to wearable sensors, energy storage materials, and actuation elements. It has been observed that directional alignment of the particle phase in the polymer dispersion can imbue the resulting composite material with enhanced mechanical, electrical, thermal or optical properties. Thus, external field-driven particle alignment during the AM process is one approach to tailoring the properties of composites for end-use applications. This review article provides an overview of externally directed field mechanisms (e.g., electric, magnetic, and acoustic) that are used for particle alignment. Illustrative examples from the AM literature show how these mechanisms are used to create structured composites with unique properties that can only be achieved through alignment. This article closes with a discussion of how particle distribution (i.e., microstructure) affects mechanical properties. A fundamental description of particle phase transport in polymers could lead to the development of AM process control for particle-polymer composite fabrication. This would ultimately create opportunities to explore the fundamental impact that alignment has on particle-polymer composite properties, which opens up the possibility of tailoring these materials for specific applications.
\end{abstract}

Keywords: directed assembly; additive manufacturing; external fields; 3D printing; particlepolymer composites

\section{Introduction}

Additive manufacturing ( $\mathrm{AM})$ is a method by which three-dimensional computeraided designs (CAD) are fabricated without the need for process planning [1]. This process involves the layer-by-layer deposition of filament, powder, or liquid drops to translate the CAD drawing into a fully realized object. The AM industry generated a revenue of approximately 5.2 billion USD in 2015 [2]. This revenue includes a 769 million USD AM materials market that produces, in descending order of market share, photopolymers, laser-sintered powders, filaments, and metals. These materials are used to support a variety of AM technologies [3] that include 3D printing, stereolithography, laminated object manufacturing, and fused deposition modeling.

Among the materials available for use in AM applications, polymers represent 51\% of the products produced by AM systems [2,4]. This fraction does not include the $29 \%$ of products that blend polymers and metals together to form composite AM materials. The ubiquity of polymers in the AM industry likely arises from their low cost and high production volume. The U.S. National Research Council reports that polymers, in the form of plastics, fibers, and rubber, are produced in the range of 71 billion pounds per year with a financial return approaching 0.50 USD per pound [5]. As a fundamental building block for AM applications, polymers have properties that can be tuned to achieve specific rheological behavior [6-8] or functionalities related to ionic conductivity [9-12], thermal conductivity [13-15], and magnetic [16-18] or dielectric [19-21] permittivity. 
While some of these polymer functionalities can be achieved through chemical modification, an alternative method is to disperse filler micro- or nanoparticles in the polymer solution prior to processing or deposition by AM [22-26]. Inks based on particle-polymer dispersions can be used in the AM process to create compositionally graded composites $[27,28]$ that serve to enhance the multi-material capabilities of finished products [29]. Tuning the AM process for particle-polymer dispersions influences composite properties such as flexibility, mechanical strength, toughness, and optical transparency [30-32]. These material properties are directly tied to the filler particle organization within the composite [33].

Directing the assembly of filler particles in a composite toward specifically organized arrangements or orientations enables the fabrication of materials which exhibit hierarchical functionality from the nanoscale to the macroscale [34]. Polymer composites that contain aligned filler particles exhibit increased elastic moduli as compared with composites where the filler particles are randomly arranged [35-38]. Particle-polymer composites with internal alignment also exhibit anisotropic responses to mechanical, thermal, electric, or magnetic inputs [39-42]. The anisotropy exhibited by the aligned particle-polymer composites can be used for a variety of emerging soft material applications, including wearable sensing devices [43-45], energy storage [46-48], artificial muscles [49-51], and soft robotics [52-54]. The alignment of filler particles used in these materials is often achieved by the application of external fields such as electric $[55,56]$, magnetic $[57,58]$, and acoustic fields [59-61].

It is the purpose of this review article to provide an overview of some of the types of external fields used to direct the assembly or alignment of filler particle-polymer dispersions. Figure 1 summarizes the transport mechanisms discussed in this review. Using external fields to tune the internal arrangement of filler particles is a pathway towards fabricating functionally graded particle-polymer composites. Achieving specific arrangements of filler particle distributions requires an understanding of how different directed assembly mechanisms operate. The forces associated with each of these mechanisms can favor different structures and a fundamental understanding of these forces serves as the basis for a paradigm in multi-material AM processing. The review concludes with a discussion of how external fields can contribute to specific filler particle arrangements that enhance intrinsic material properties (e.g., elastic modulus) or can be used as an actuator to improve AM process control.

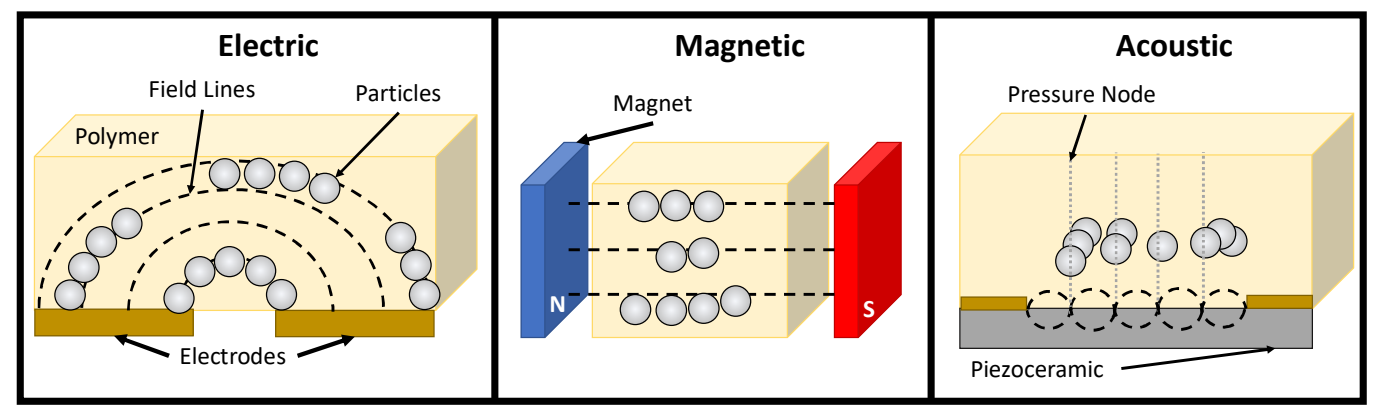

Figure 1. The diagram shows the three major types of external field mechanisms used in AM processing of particle-polymer composites.

\section{Electric Fields}

In uniform electric fields, or at low frequencies, particle transport is dominated by electrophoresis, which represents the migration of a charged particle towards an electrode of opposite polarity. The characteristic electrophoretic velocity as a function of frequency is $[62,63]$ :

$$
v_{e p}=\left(b \varepsilon_{p} \varepsilon_{o} \zeta E / \eta m_{p}\right)\left[\left(b / m_{p}\right)^{2}+\omega^{2}\right]^{-0.5}
$$


where $b$ is the Stokes drag factor, $\varepsilon_{p}$ is the dielectric constant of the particle, $\varepsilon_{0}$ is the electric permittivity of free space, $\zeta$ is the particle zeta potential, $E$ is the applied electric field, $\eta$ is the medium viscosity, $m_{p}$ is the particle mass, and $\omega$ is the angular frequency of the field. Electrophoresis is frequently used to deposit colloidal particles onto surfaces to create functional materials by a process known as electrophoretic deposition [64,65].

In one demonstration of electrophoretic deposition for fabricating particle-polymer composites, poly [3-(3-N,N-diethylaminopropoxy)thiophene] (PDAOT) was dissolved in an acetic acid, water, and ethanol mixture [66]. The mixture was blended with a dispersion of single-wall carbon nanotubes (SWCNTs) and placed in an electrochemical cell, where a 3-15 V direct current (DC) potential was applied over a period of time that varied from 1 to $10 \mathrm{~min}$. The process was used to control the particle-polymer deposition rate for the fabrication of metal oxide nanoparticle-polymer films with a thickness that varied from $100 \mathrm{~nm}$ to $15 \mu \mathrm{m}[67,68]$. Another polymer, poly (3-octylthiophene) (P3OT), has been blended with SWCNTs to fabricate particle-polymer films with enhanced current density [69]. In these experiments, a $40 \mathrm{~V}$ DC potential was applied to create a control particle-polymer film. An alternating current (AC) signal was superimposed onto the input DC signal, resulting in a $12 \%$ improvement to current density capacity. The current capacity of electrophoretically deposited particle-polymer films was used as the basis for a sensor which measured changes in resistivity due to in-plane shear stress [70].

Electrodes can also be patterned using photolithography to better concentrate deposition material. Electrode patterning allowed for the fabrication of a conductive particlepolymer film that resulted in a 344\% improvement of current density as compared with films fabricated using a DC potential [69]. Photolithography has also been used as part of a process to create a substrate where electrophoretic deposition was applied to Ni fibers dispersed in a polyurethane-modified epoxy resin [71]. An unmodified resin was measured, and its Young's modulus was $285 \mathrm{MPa}$ after curing, while an electrophoretically deposited Ni fiber resin composite's Young's modulus was 6.8 GPa.

When a non-uniform electric field is used, particles migrate towards field minima or maxima depending on particle and medium properties [72-74]. This mechanism, known as dielectrophoresis, affects particles with a force that depends on the gradient of the applied electric field [75]:

$$
F_{\text {dep }}=\frac{3}{2} \varepsilon_{m} \varepsilon_{0} V_{p} f_{c m} \nabla E^{2},
$$

where $\varepsilon_{m}$ is the medium dielectric constant, $V_{p}$ is the particle volume, and $f_{c m}$ is the ClausiusMossotti factor. The parameter, $f_{c m}$, is a factor that compares the relative contribution of particle and medium properties to the force acting on the particle. This contribution is as follows:

$$
f_{c m}=\operatorname{Re}\left[\left(\widetilde{\varepsilon}_{p}-\widetilde{\varepsilon}_{m}\right) /\left(\widetilde{\varepsilon}_{p}+2 \widetilde{\varepsilon}_{m}\right)\right]
$$

where the operator, $R e$, is used to find the real component of the Clausius-Mossotti term and $\widetilde{\varepsilon}=\varepsilon \varepsilon_{0}-i \sigma / \omega$ is the complex dielectric permittivity of the particle or the medium. In the DC limit, where $\omega=0, f_{c m}$ is dominated by conductivity values, while dielectric constants are important at high frequencies $(\omega \rightarrow \infty)$ [76].

Dipolar chains also form in response to electric field-induced polarization of the particles in solution. The dipolar chain energy acting on a single pair of particles in an electric field is [77]:

$$
u_{d c, E}=-\frac{p^{2}}{2 \pi \varepsilon_{m} \varepsilon_{o} r^{3}} P_{2}(\cos \theta),
$$

where $p=3 \varepsilon_{m} \varepsilon_{0} V_{p} f_{c m} E$ is the dipole moment of the particle pair, $r$ is the center-to-center separation distance between particle pairs, $P_{2}$ is a Legendre polynomial of order two, and $\theta$ is the angular orientation of the particle pair with respect to the direction of the applied electric field. The force representation of Equation (4) is [78]:

$$
F_{d c, E}=-\frac{p^{2}}{4 \pi \varepsilon_{m} \varepsilon_{0} r^{4}}\left[\left(15 \cos ^{2} \theta-3\right) e_{r}-(6 \cos \theta) e_{z}\right]
$$


where $e_{r}$ is a unit vector that connects the particle pair and $e_{z}$ is a unit vector that points in the direction of the electric field.

In uniform electric fields or electric fields with weak gradients, dipolar chain structures are observed in the resulting composite. These dipolar chains assemble with structures oriented in the primary direction of the applied electric field and, with particle loadings in sufficiently high concentrations, bridge the gap between electrodes, forming a percolated network. Spirulina, a microscopic organism with a spring-like structure, is coated with silver and dispersed in polydimethylsiloxane (PDMS) [79]. The Spirulina structures are used to create microcoils, as shown in Figure 2A. These microcoil particles assemble into chains between electrodes to form a composite with a conductivity of $10 \mathrm{~S} / \mathrm{m}$, which is eight orders of magnitude larger than non-aligned Spirulina samples (Figure 2B). Carbon nanocones dispersed in an acrylated urethane form chain structures that improve the electrical conductivity of the polymer from $10^{-7}$ to $10^{-3} \mathrm{~S} / \mathrm{m}[80]$.
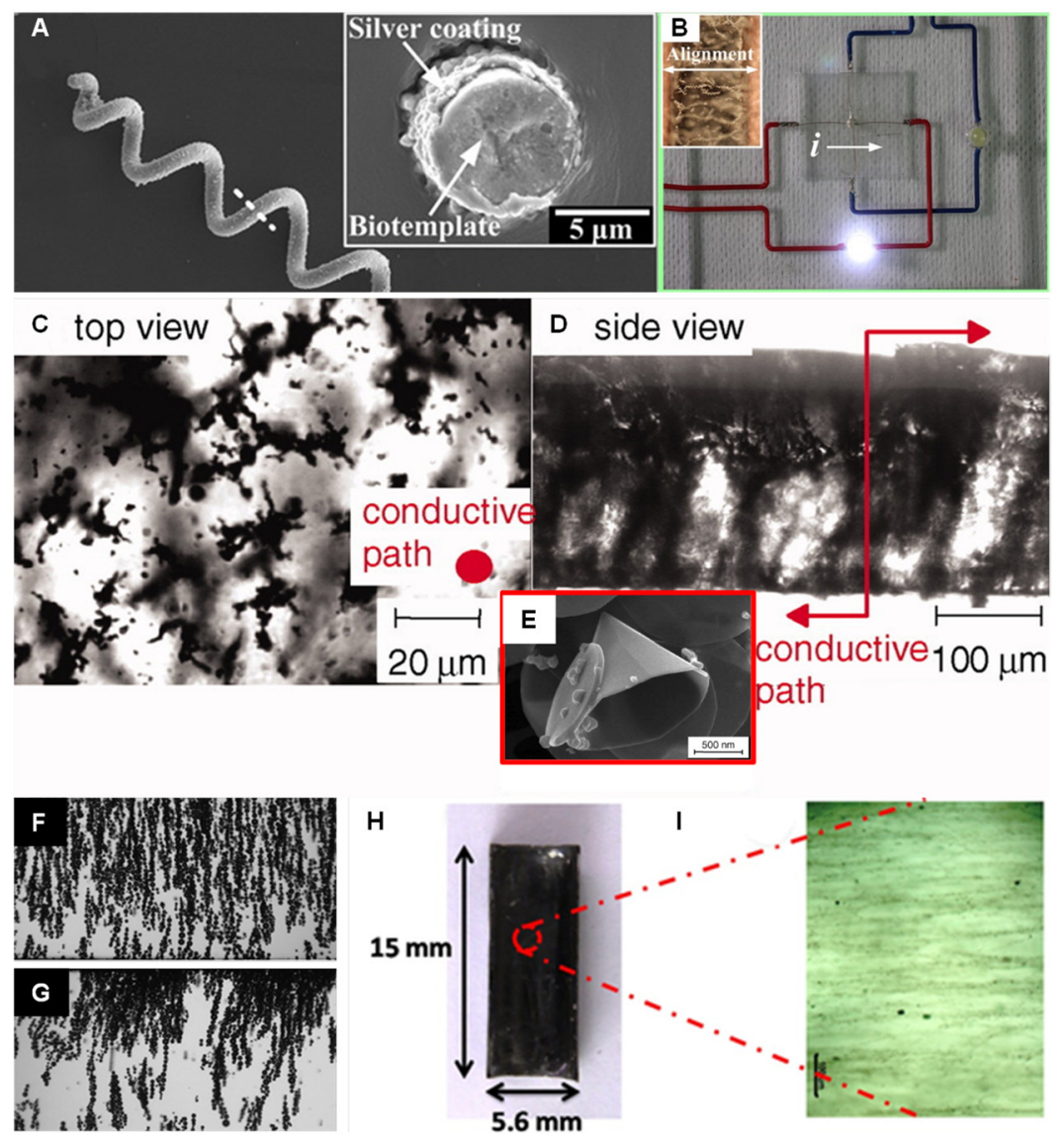

Figure 2. (A) SEM image of a metallic Spirulina-templated microcoil. The inset shows a crosssection of the microcoil particle; (B) the application of a $5 \mathrm{wt} \%$ electric field-aligned microcoil/PDMS composite in a functional LED integrated circuit. Reprinted with permission from [79], copyright 2017 American Chemical Society; optical micrographs showing (C) the top view and (D) side view of a thermally cured carbon nanocone film ( $0.2 \mathrm{vol} \%)$, which was assembled by DC field alignment; (E) inset shows an SEM image of the nanocone used in this process. Reprinted with permission from [80], copyright 2011 John Wiley and Sons; (F) hollow glass microspheres dispersed in Norland optical adhesive initially chain before (G) migrating towards an electrode. Reprinted with permission from [81], copyright 2017 Elsevier; (H) an acrylate polymer composite consisting of (I) SWCNT aligned using an AC electric field. Reprinted with permission from [82], copyright 2014 John Wiley and Sons.

Particle-polymer composites fabricated using electric field assembly can be used to fabricate tactile force sensors. For example, carbon nanocones dispersed in a UV curable 
adhesive, 3094 Dymax, were assembled into a wire that connects two electrodes spaced $100 \mu \mathrm{m}$ apart, as shown in Figure 2D [83]. The carbon nanocone wire formed as part of the composite was found to be sensitive to substrate deflections up to $50 \mu \mathrm{m}$. CNTs dispersed in PDMS assembled between interdigitated electrodes formed microwires that registered a $0.145 \%$ linear change in wire resistivity per unit change in $\mathrm{mN}$ of applied force [84].

When dielectrophoresis is the dominant transport mechanism, chains form locally in the electric field before migrating towards electric field minima or maxima $[74,85]$. This can create opportunities to fabricate local concentration gradients in composite materials. The dynamics of particle chain formation in a polymer media under dielectrophoresis mechanism can be predicted using a particle chaining model based on dipole-dipole interactions, which takes into account variable medium viscosity and electric field amplitude [86]. Hollow glass spheres dispersed in Norland optical adhesive initially form chains (Figure 2F) before migrating towards an electrode (Figure 2G) [81]. Barium titanate nanoparticles with a cubic morphology migrate towards electrodes, forming a particle rich layer, when dispersed in PDMS [87]. Anisotropic particles, such as CNTs or fibers, experience an electric field-induced torque before migration towards an electrode, enabling the formation of an aligned nanocomposite (Figure 2H,I) $[82,88,89]$. The local concentration gradients formed in this way have been used to fabricate composite materials tailored to serve as alternatives to metallic strain gauges [90] or create thermally conductive pathways for enhanced heat transfer [91,92].

\section{Magnetic Fields}

Similar as with electric fields, particles respond to magnetic fields by migrating towards magnetic field minima or maxima depending on the intrinsic properties of the particle and the medium in which they are dispersed [93]. The magnetophoretic force responsible for this migration is given as follows:

$$
F_{m a g}=\frac{\left(\chi_{p}-\chi_{m}\right) V_{p}}{\mu_{o}\left(1+\chi_{m}\right)}(B \cdot \nabla B),
$$

where $\chi_{p}$ and $\chi_{m}$ are the magnetic susceptibilities of the particle and medium, respectively, and $\mu_{0}$ is the magnetic permeability of free space. The magnetic induction, $B$, is related to the applied magnetic field, $H$, by the expression [94] $B=\mu_{0}\left(1+\chi_{m}\right) H$. In addition to magnetophoresis, multiple particles also form dipolar chains in the direction of the magnetic field. The interaction energy between a single pair of particles in a magnetic field is [95]:

$$
u_{d c, M}=-\frac{1.202 m^{2}}{2 \pi \mu_{o} r^{3}} P_{2}(\cos \theta)
$$

where $m=\left(\chi_{p}-\chi_{m}\right) V_{p} B / \mu_{o}$ is the magnetic moment of the particle and $\theta$ is the angle the pair forms with respect to the direction of the magnetic field. The force representation of Equation (7) is [96]:

$$
F_{d c, M}=\frac{3 \mu_{o} m^{2}}{4 \pi r^{4}}\left[\left(1-5 \cos ^{2} \theta\right) \boldsymbol{e}_{r}+(2 \cos \theta) \boldsymbol{e}_{z}\right],
$$

where $e_{r}$ is a unit vector that connects the particle pair and $e_{z}$ is a unit vector that points in the direction of the magnetic field.

The use of magnets as a mechanism for composite fabrication has a long history due to the ease of the process and simplicity of blending para- or ferromagnetic particles with a polymer medium [97-101]. When magnetically sensitive particles are crosslinked in a polymer, the composite forms a magnetoelastomer that deforms in the presence of a magnetic field [102,103]. An alternative method for creating magnetoelastomers was suggested by the authors of this review [104]. In this alternative approach, a sacrificial scaffold was created in PDMS. The scaffold was dissolved, and a magnetorheological fluid 
was introduced to the evacuated channel, rendering the structure sensitive to magnetic field-induced deflections.

Magnetoelastic soft actuators (sometimes referred to as ferrogels) are designed by coupling magnetic properties of filler particles and elasticity of the polymer matrix. Understanding the deformation and mechanical properties of such actuators is crucial for optimizing their performance [105]. The deformation of these composites in the presence of a magnetic field is analogous to muscle constriction [106], which makes these types of composites ideal for actuation applications such as haptic control surfaces for steering [107].

Magnetite $\left(\mathrm{Fe}_{3} \mathrm{O}_{4}\right)$ is one of the most frequently used filler material due to its high magnetic susceptibility [108], which makes it easy to pattern structures in polymers using externally directed magnetic fields [109]. $\mathrm{Fe}_{3} \mathrm{O}_{4}$ can be adsorbed on cellulose nanocrystals to fabricate magnetic cellulose nanocrystals (MGCNCs). The MGCNCs, shown in Figure 3, then are aligned in different configurations (parallel or perpendicular directions) in the polylactic acid matrix through a tunable magnetic field which result in fabrication of particle-polymer nanocomposite with anisotropic electrical and magnetic properties. The percent elongation improvement of the resulting nanocomposite is in the range of $60 \%$ to $240 \%$ [110]. This use of magnetic fields to locally pattern magnetite-PDMS composites led to a reduction in local elastic modulus by as much as $50 \%$ depending on filler particle concentration. While local elastic properties of the composite may see a reduction due to magnetic field-induced concentration, the bulk storage moduli of a magnetite-based composite are observed to increase by a factor of two depending on the field magnitude used to align particles [111]. Magnetite can also be functionally bound to materials that are not ferromagnetic, such as cellulose [112] or glass [113], to create materials with anisotropic mechanical properties or functional structures, like the circuit shown in Figure 4A,B.
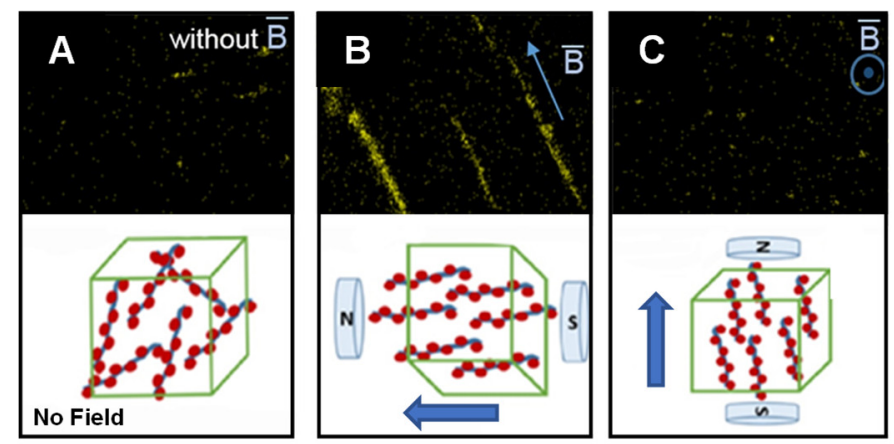

Figure 3. Energy dispersive x-ray images show magnetic cellulose nanocrystals (MGCNC) without (A) an applied magnetic field, (B) a horizontally aligned magnetic field, and (C) a vertically aligned magnetic field. Insets diagrammatically show the field alignment for each case. Reprinted with permission from [113]. Copyright 2011 American Chemical Society. 

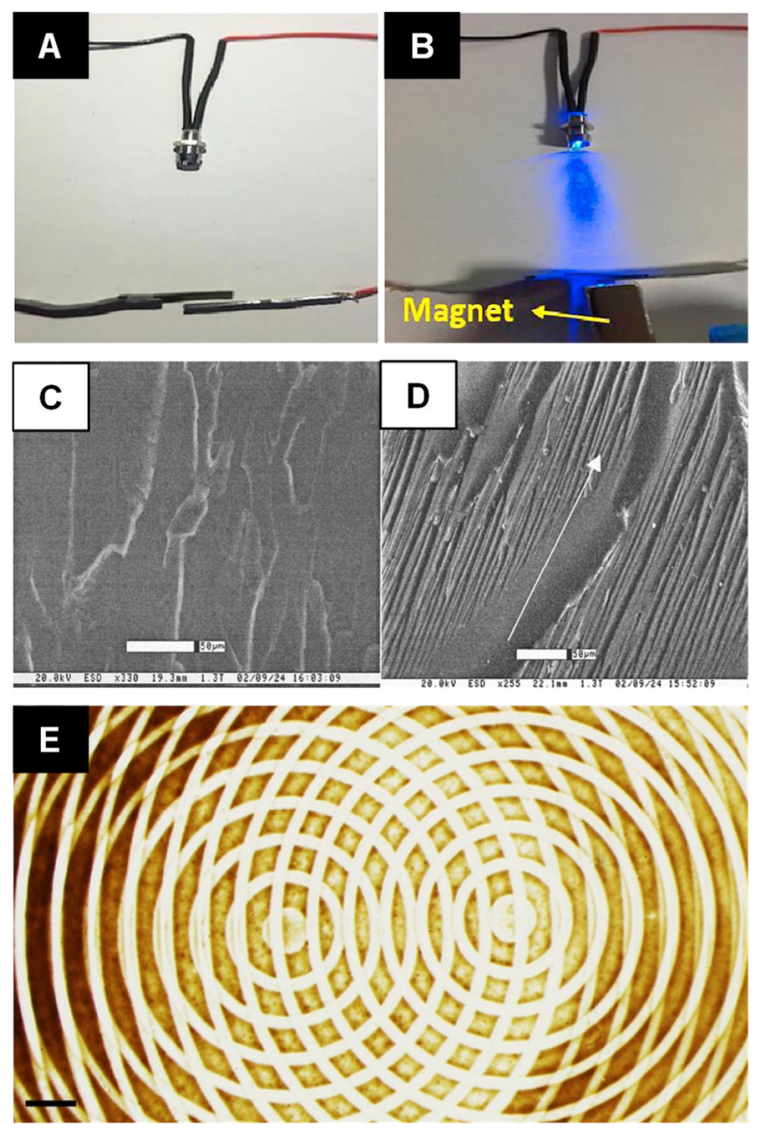

Figure 4. A nanocomposite magnetic switch: (A) a gap between an aligned CNT coated composite and a nonmagnetic $\mathrm{Pb}$ is $(\mathbf{B})$ closed when a magnet is placed underneath the $\mathrm{Pb}$ sheet, which lights an LED. Reprinted with permission from [112]. Copyright 2019 Elsevier. Environmental scanning electron microscopy images show the morphology of an epoxy composite sample processed at (C) no applied magnetic field and (D) at $15 \mathrm{~T}$. The arrow represents the direction of the corresponding magnetic field. Reprinted with permission from [114]. Copyright 2004 John Wiley and Sons. (E) A complex pattern formed in a composite by the superposition of two separate magnetic fields. Reprinted with permission from [115]. Copyright 2017 Springer Nature.

Aside from magnetite, carbon nanotubes (CNTs) are also extensively used with magnetic fields to create aligned composites [116-118]. When a magnetic field is applied to anisotropic particle like CNT, the particle rotates with a torque of [119],

$$
\tau_{m a g}=m \mu_{o} H \sin \left(\varphi_{f}-\varphi_{p}\right)
$$

where $\varphi_{f}$ is the angular orientation of the magnetic field and $\varphi_{p}$ is the angular orientation of the particle. Multi-walled and single-walled CNTs blended into two separate types of epoxy exhibit different mechanical properties as a function of magnetic field strength [120]. Multi-walled CNTs blended with a bisphenol-A type epoxy (Figure 4C,D) only exhibits a small $(\sim 25 \%)$ increase in elastic modulus as a function of magnetic field strength, up to 25 T. However, single-walled CNTs increase the elastic modulus by a factor of nearly two when the same alignment process is used. A separate epoxy based on bisphenol-A and bisphenol-F actually exhibit a decline in elastic modulus for both dispersions based on both types of CNTs. This is probably due to the interaction between the magnetic field and the dipole of the polymer [114].

Since the magnetophoretic effect scales volumetrically, strong magnetic fields can induce dipole alignment in both the filler particle and the polymer. $\mathrm{Fe}_{3} \mathrm{O}_{4}$ magnetic nanoparticles were assembled within PMMA film by magnetophoretic forces using two 
permanent magnets, one was stationary and the other was manipulated in order to create complex interference-like patterns (Figure 4F) [115]. Low-strength magnetic fields are sometimes used to minimize the complex effects that polymer alignment has on the mechanical properties of the composite [121]. The susceptibility of CNTs to low-strength magnetic fields is typically enhanced by blending with iron oxide particles. This blending process allows for filler particle alignment at magnetic field strengths as low as $0.5 \mathrm{~T}$ in a rubber medium, which improves the compressive strength by as much as $285 \%$ as compared with rubber alone [122]. Another process uses acids to oxidize CNTs and create functional groups, after which the CNTs are placed in a mixture containing ferrous sulfate and iron (III) chloride and stirred together in ammonia to initiate a reaction that attaches magnetite to the functional groups [123]. The magnetite/CNT particles are dispersed in a bisphenol-A (DGEBA)/polyoxypropylenediamine epoxy and cured during exposure to a $0.7 \mathrm{~T}$ magnetic field. The composites made from these particles are observed to have a lower crack density than epoxy laminate in the absence of particles, which is ideal for composites that undergo thermal cycling.

Another process uses surfactants to tether single-walled CNTs to $50 \mathrm{~nm} \gamma$-iron (III) oxide particles [124]. This process enables a 1-2 wt\% nanoparticle-CNT dispersion to assemble into aligned microstructures in an epoxy composed of a bisphenol A polymer. The composites formed by this process exhibit a $9.8 \%$ increase in ultimate tensile strength. The enhanced mechanical properties of the composite are brought on by field aligned CNT/iron particles [125]. Anisotropic mechanical properties enable particle-polymer composites based on magnetic alignment to exhibit bending modes that enable the fabrication of soft actuation elements [53].

Aside from mechanical properties, magnetic alignment of particles can also enhance electrical properties of the composite. Magnetite particles aligned in a $25 \mathrm{mT}$ magnetic field have been observed to increase the electric conductivity from $7.14 \times 10^{-9} \mathrm{~S} / \mathrm{m}$ for a randomly dispersed sample to $0.0014 \mathrm{~S} / \mathrm{m}$ for aligned samples [126]. The enhancement in electric conductivity also extends to magnetite-functionalized CNT particles, where aligned dispersions prepared in a bisphenol A/methylenedianiline epoxy exhibit conductivities of $0.5 \mathrm{~S} / \mathrm{m}$ [127]. The increase in conductivity is greatest in the direction of particle alignment, while conductivity is reduced in a direction perpendicular to alignment. Aligned particlepolymer composites undergo linear changes in resistance as a function of strain, with applications to mechanical sensing [128].

The process of aligning particles can also lead to enhancements in thermal conductivity. Values of $1.43 \mathrm{~W} / \mathrm{m}-\mathrm{K}$ for thermal conductivity have been observed in the direction of alignment for $40 \mathrm{vol} \%$ of magnetite dispersed in epoxy [129]. Similar values of thermal conductivity have been observed for magnetite-coated diamond particles, although only a volume fraction of $15 \%$ was necessary in this case [130]. Thermal conductivities of $\sim 5 \mathrm{~W} / \mathrm{m}-\mathrm{K}$ have been observed for aligned nickel particles in a polymer matrix, which represented an increase of as much as $175 \%$ over the polymer alone [131]. Composites formed from CNTs dispersed in a polyvinyldene fluoride matrix have exhibited thermal resistances as low as $11 \times 10^{-9} \mathrm{~m}^{2} \mathrm{~K} / \mathrm{W}$ [132]. Modification of thermal conductivity by filler particle assembly can be used to improve thermal interfacing between surfaces [133] or retard thermal transport [134].

\section{Acoustic Fields}

An acoustic source, such as a piezeoelectric transducer, generates an acoustic radiation force that can be used to transport particles. The acoustic radiation force responsible for transporting particles is dependent on the gradient of the pressure field generated by the acoustic source [135-137]:

$$
\begin{gathered}
F_{a c}=\frac{\pi \beta_{m} V_{p} \Phi}{2 \lambda} \nabla P^{2}, \\
\Phi=\frac{5 \rho_{p}-2 \rho_{m}}{2 \rho_{p}+\rho_{m}}-\frac{\beta_{p}}{\beta_{m}}
\end{gathered}
$$


where $\beta=1 / \rho c^{2}$ is the compressibility, $\rho$ is density, $c$ is the speed of sound, $\Phi$ is the acoustic contrast factor, $\lambda$ is the wavelength of the acoustic field, and $P$ is the pressure distribution. The subscripts $p$ and $m$ refer to particle and medium properties, respectively. The pressure distribution for a one-dimensional standing wave is [138] $P=P_{o} \cos \left(2 \pi f x / c_{m}\right)$, where $P_{o}$ is the pressure amplitude and $f$ is the applied frequency.

Acoustic nodes are created when the acoustic wave is reflected. The resulting superposition of incident and reflected waves interfere with each other [139]. This phenomena, known as standing acoustic waves (SAW), has long been recognized as a method for separating small particles or drops dispersed in a fluid [135,140-142]. The relative difference in particle density and compressibility dictates whether particles migrate towards or away from the acoustic pressure node where the wave interference leads to a local pressure of zero. Particles that are more dense and less compressible than the medium, such as polystyrene [143] or cells [144], migrate to acoustic pressure nodes. Particles such as microbubbles [145] or PDMS [146] are less dense or more compressible than the medium in which they are dispersed, leading to migration towards the acoustic pressure antinode, where the pressure gradient is highest.

To demonstrate the utility of SAWs as a method for particle-polymer composite fabrication, early studies used polysiloxane as the polymer medium due to its ease of use and low cost [147]. The composite was prepared by blending the polysiloxane with a curing agent at a ratio of 20:1. Ten-micron acrylic spheres were dispersed in the polysiloxane fluid to act as filler particles. The acoustic field frequency was adjusted to create multiple acoustic nodes for filler particle assembly and allowed to set for $8 \mathrm{~h}$. Adjusting the orientation and number of transducers can lead to different internal microstructures, such as lines or lattices [148]. Diffraction experiments showed that acoustic fields were excellent for localizing particles around the acoustic node [149]. Diamond nanoparticles with diameters of $5 \mathrm{~nm}$ were successfully arranged in ethanol-diluted epoxy matrix using acoustic standing wave to produce polymer nanocomposite. The radiation force of standing waves in a rectangular chamber was used to pattern clusters of nanoparticles. During the epoxy curing cycle of $5 \mathrm{~min}$, the standing wave was activated and diamond nanoparticles migrated toward the nodes due to acoustic radiation force and formed quasi-parallel planes of particle clusters (Figure 5A) [150]. Complex particle-polymer composite structures can be formed using SAWs if the acoustic signal is first passed through a pattern that acts like a "hologram" for the desired structure (e.g., Figure 5B) [151-153]. 

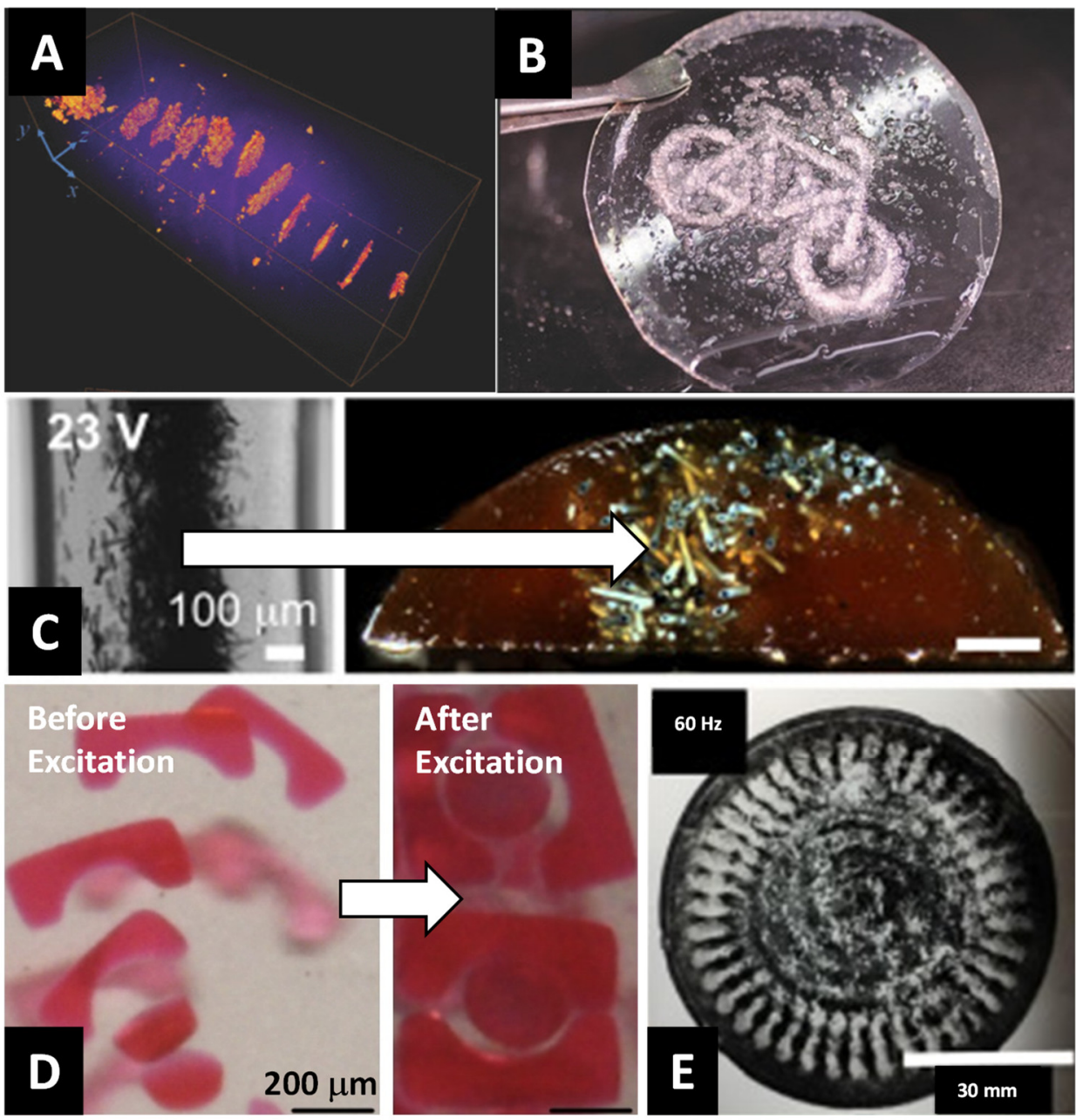

Figure 5. (A) An X-ray microtomographic rendering of $\sim 5 \mathrm{~nm}$ diamond nanoparticles assembled in an epoxy composite using a $1 \mathrm{MHz}$ ultrasound standing wave. Reprinted with permission from [150], copyright 2011 AIP Publishing; (B) holographic tweezers used acoustic fields to assemble silicone particles to form complex, nonsymmetric structures. Reprinted with permission from [153], copyright 2011 John Wiley and Sons; (C, left) acoustically assembled fibers assembled at an acoustic node in an epoxy; (C, right) the composite is deposited on a substrate at a rate of $3.7 \mathrm{~mm} / \mathrm{s}$ to form a printed line. Reprinted with permission from [154], copyright 2016 Elsevier; (D) lock (1 mm square) and key (200 $\mu \mathrm{m}$ circle) microgel assemble before excitation (left) and after acoustic excitation (right). Reprinted with permission from [155], copyright 2011 Elsevier; (E) iron oxide nanoparticles (50-100 nm) assemble in a hydrogel through vibrational excitation of the medium. Reprinted with permission from [60], copyright 2018 Elsevier.

Localizing particles at the node has be done by adjusting the input voltage into the piezoelectric transducer, which linearly scales with applied pressure amplitude [156]. Tuning the input voltage controls the degree of particle ensemble compression, which affects the equilibrium particle microstructure during transport within the acoustic field $[61,157,158]$. This creates opportunities to use SAWs as a method to dynamically control the internal arrangement of filler particles at the acoustic node during 3D printing. For example, a base ink used for 3D printing consisting of a thermally curable epoxy resin and polydisperse glass spheres has been extruded through a printhead with a piezoelectric transducer and demonstrated the fabrication of a log pile structure formed with internally structured particle-polymer composite lines (e.g., Figure 5C) [159]. Multiple lines have been formed during the extrusion process when the ink was blended with negative and positive acoustic contrast particles [154]. SAWs has also been used during the sterolithography process 
where piezoelectric transducers could be attached to a vat holding a photocurable polymer to hold particles in place during the curing phase [160]. Multiple piezoelectric transducers were used during the stereolithography process to assemble CNTs that enhanced the electric conductivity of the resulting particle-polymer composite [161].

SAWs can also be used to orient and assemble anisotropic particles. The forces that arise from these mechanisms drive anisotropic particles such as rods, bricks, or bowtie shapes to orient themselves in a direction that is parallel to the acoustic node [162]. These forces have been used to assemble glass fibers dispersed in a dimethacrylate monomer fluid $[59,163]$. SAWs were used to generate periodic arrays of pressure nodes and antinodes and trap stimulus-responsive coacervate microdroplets to fabricate parallel lines and gridlike micropatterned polymer/dipeptide droplets [164]. Acoustic fields have been used to assemble fibers on a timescale of $\sim 667 \mathrm{~ms}$ and photocured with an LED light for a period of $40 \mathrm{~s}$ to create a composite that improved the tensile strength by a factor of $43 \%$ as compared with a randomly distributed sample. The light source used to cure the sample could be mounted to a 3D printer gantry to locally cure the acoustically assembled fiberpolymer composite [165]. Acoustic fields have also been applied to assemble CNTs in a thermosetting polymer resin, which improves the ultimate tensile strength by $6 \%$ and the elastic modulus by $51 \%$ [166].

SAWs have been used to fabricate biological composites due to observations that cells do not appear to exhibit long-term effects because of acoustic field exposure [167,168]. Yeast cells dispersed in acrylamide or alginate gels assembled at acoustic nodes in $10 \mathrm{~min}$ and cured in approximately $1 \mathrm{~min}$ after the assembly process was complete $[169,170]$. The cells concentrated at the acoustic node remodeled the surrounding gel matrix where the cells locally caused the gel network to contract [171]. The process of concentrating cells at an acoustic node enabled the study of cell-cell interactions, which was not possible for isotropically distributed cells. A live/dead assay performed on acoustically assembled biocomposites showed that approximately $50 \%$ of the cells in the sample remained viable

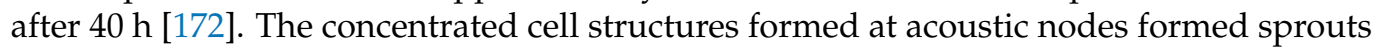
that were nearly three times longer than those formed in samples not directly exposed to the SAW, indicating the formation of vasculature [173]. Cells seeded in isolated hydrogel beads assembled into complex 3D structures (Figure 5D) that could serve as model tissues for a variety of biotechnology applications [155]. Alternative approaches for creating hydrogel-based biocomposites have relied on modification of the AM platform to assembly cells during the extrusion process [174] or to break the surface tension at the nozzle tip to create tunable hydrogel droplets [175].

An alternative method for transmitting acoustic waves is to have the waves pass through a substrate rather than into the fluid directly. This type of wave is known as a surface standing acoustic wave (SSAW) and the acoustic radiation force experienced by particles remains the same as the one presented above [176]. A chamber placed on top of a vibration generator was used to produce SSAWs that directed the assembly of cellular spheroid colonies consisting of mouse fibroblasts dispersed in crosslinked fibrinogen [177]. The same method was applied to assemble cardiomyocytes into a model cardiac tissue [178]. Cardiomyocytes assembled in this way exhibited 2.5 times greater contractile stress and faster beating after 5 days as compared with randomly distributed samples. SSAWs can also be generated using electrodes patterned on a piezoelectric substrate, which was used to assemble cardiomyocytes in a photocurable gelatin [179]. The cardiomyocytes exhibited beating in 5 to 7 days after assembly.

The patterns observed in samples assembled using SSAWs resemble Chladni figures [180], which result from time-varying localized flexing of the substrate. This flexing causes the appearance of acoustic nodes, which correspond to plate displacement anti-nodes (i.e., where displacement is maximal or minimal) [181]. A comparison of microparticle and nanoparticle assembly in a PEGDA hydrogel showed that microparticles preferentially migrate to the acoustic nodes, while the nanoparticles migrate away from the acoustic nodes [60]. A scaling analysis of this phenomena showed that nanoparticles 
were likely entrained in an acoustically generated flow known as acoustic streaming [182]. Assuming spherical geometry, the characteristic acoustic streaming velocity is [183]:

$$
v_{s t r}=\frac{3}{16} \frac{P_{o}^{2}}{\rho_{m}^{2} c_{m}^{3}} \sin (2 k x+N \pi),
$$

where $m$ is the solvent viscosity, $k=\omega / c_{m}$ is the wave number, $\omega$ is the acoustic field frequency, and $N=\omega w / \pi c_{m}$ is the number of acoustic nodes in a system with a characteristic width of $w$. To the best of our knowledge, the work by Shabaniverki et al. [60], shown in Figure 5E, is the only demonstration of acoustic streaming as a transport mechanism applied to AM.

\section{Future Directions and Conclusions}

Applying external fields to particles dispersed in a polymer solution creates opportunities to target specific mechanical properties by tuning particle microstructure through alignment. Halpin and Tsai were the first to develop models that described the mechanical properties of particles aligned in a composite [184,185]:

$$
\begin{gathered}
\frac{E}{E_{0}}=\frac{1+\eta \phi}{1-\eta \phi^{\prime}} \\
\eta=\frac{\frac{E_{p}}{E_{o}}-1}{\frac{E_{p}}{E_{o}}+\xi^{\prime}} \\
\xi=\frac{L}{a},
\end{gathered}
$$

where $E_{o}$ is Young's modulus of the polymer in the absence of particles, $E_{p}$ is Young's modulus of the particle phase, $\phi$ is the particle volume fraction, $L$ is the length of the particle, and $a$ is the particle's radius. While the Halpin-Tsai model is frequently used to analyze composites with aligned fillers, it suffers from several deficiencies $[186,187]$ : (1) It is a semi-empirical model that does not provide any insight into particle-particle interactions and (2) it assumes that all the constituent particles are perfectly aligned. In order to overcome some of these limitations, it is necessary to incorporate the statistical distribution of particles through a parameter, such as the radial distribution function (RDF). The RDF is a probability density function that describes the distribution of particles in the sample as a function of particle pair separation. Song and Zheng [188] suggested an expression originally developed by Verberg et al. [189]:

$$
\frac{E}{E_{o}}=\chi\left[1+\frac{1.44 \phi^{2} \chi^{2}}{1-0.1241 \phi+10.46 \phi^{2}}\right],
$$

where $\chi$ is the RDF at contact between particles. This expression was originally derived from a statistical mechanics analysis of hard spheres dispersed in a Newtonian fluid. However, the polymers used in AM typically exhibit viscoelastic behavior [190]. Experimental observations of particles dispersed in a viscoelastic fluid flowing in a tube show that particles may preferentially migrate towards channel walls [191,192]. Viscoelasticity can also lead to particles chaining when subject to applied shear [193-195]. The stress distribution around individual particles causes particles to assemble into chains when sheared in a viscoelastic fluid (Figure 6) [196]. Additional work is needed to clarify the role that viscoelasticity plays in determining particle distribution in shear flow, particularly, how it applies to AM. 


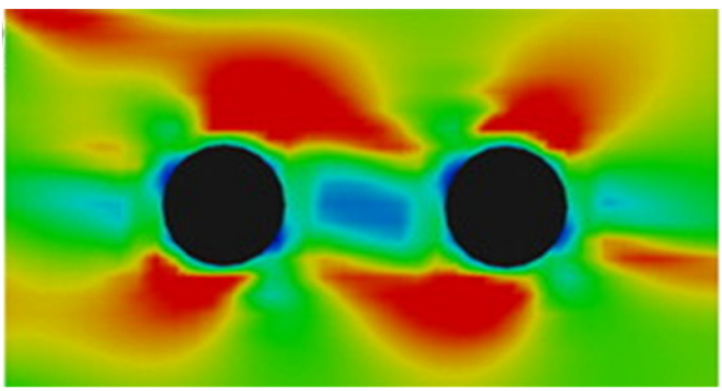

Figure 6. Simulation of a sheared particle pair in a viscoelastic fluid. The stress in the fluid favors chaining the direction of shear. Reprinted with permission from [196], copyright 2014 Elsevier.

While the model described by Equation (16) is incomplete, it does offer some insight that is not available from the Halpin-Tsai model. Equation (16) includes particle interactions (i.e., hard sphere) and incorporates particle distribution in the form of the RDF. Limitations include the assumption that particle distribution is isotropic, which would not be true for field aligned particles and is reportedly valid for bulk volume fractions below 0.55, which precludes its use in modeling the AM of solidified structures, such as colloidal crystals [197]. Measurements performed by Akella et al. on 3D printed particle-polymer fibers showed that the model described by Equation (13) was consistent for samples with random distributions of particles [198]. However, when an acoustic field was used to assemble the particles during printing, the fiber printed by Akella et al. exhibited an increase in $\chi$ due to improved particle packing. More experimental work is necessary to help elucidate the impact that RDF has on composite mechanical properties. Another potential avenue of research is the development of analytical expressions that better describe composite mechanical properties and their dependency on particle alignment and RDF.

The mechanical properties of composites with external field aligned particles have been shown to exhibit an orientational dependence, as shown in Figure 7A,B [35,199]. We can qualitatively observe this dependence by introducing an orientation parameter, $\theta$, to the RDF, which is the same as the direction of alignment from Equations (4) and (7) [200]:

$$
\chi \approx \chi_{h s} \exp \left(\Lambda\left[\frac{3 \cos ^{2} \theta-1}{2}\right]\right)
$$

where $\chi_{h s}$ is the RDF at contact for hard spheres [201], $\chi_{h s}=(1-0.5 \phi)(1-\phi)^{-3}$, and $\Lambda$ is a dimensionless field energy density, which are given in Table 1 for the mechanisms described in this review. The effect of the field-driven particle alignment on mechanical strength can also be seen in Akella et al. [198], who found that the Young's modulus increased from 24.7 MPa for the fiber without particles to $50.5 \mathrm{MPa}$ for a fiber with acoustically assembled particles. 

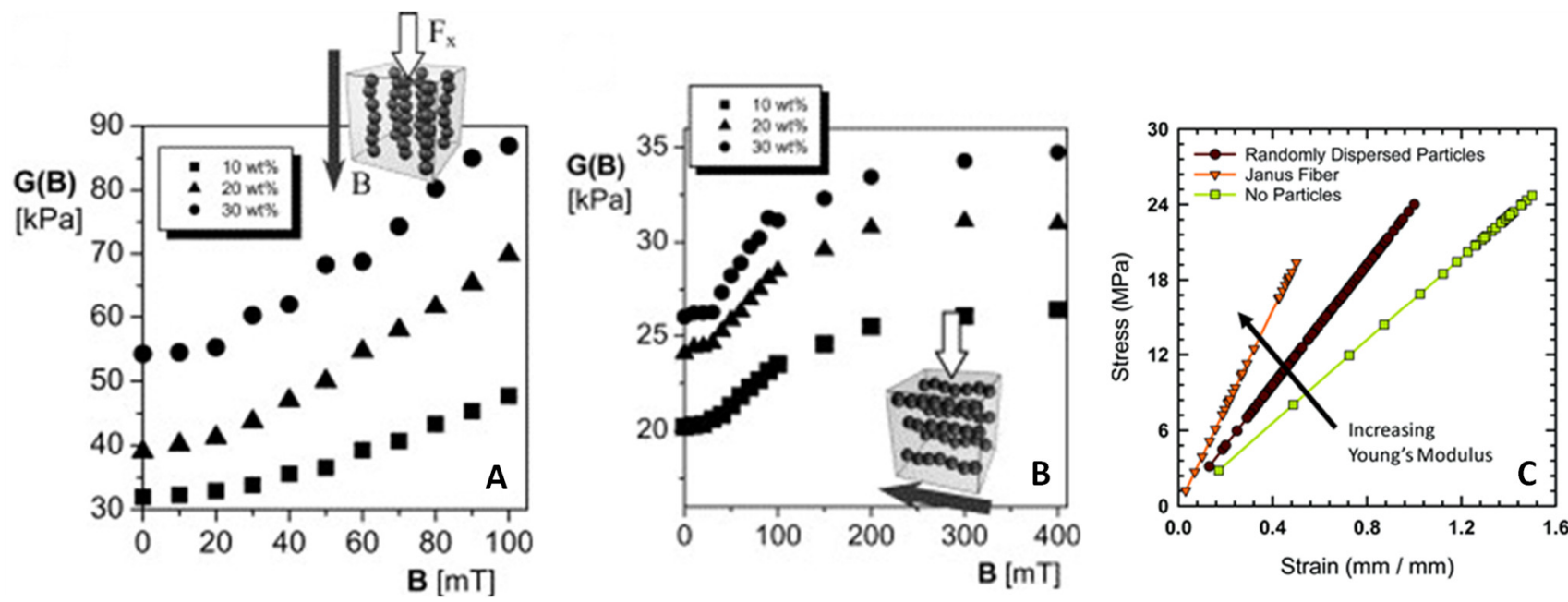

Figure 7. Elastic moduli for a composite of magnetically aligned particles with the load applied: (A) In the direction of alignment; (B) in the transverse direction of alignment. Reprinted with permission from [35], copyright 2006 Elsevier. (C) Stress-strain curves for a 3D printed fiber without particles (squares), with randomly distributed particles (circles), and acoustically assembled particles (triangles). Reprinted with permission from [198], copyright 2020 Royal Society of Chemistry.

Table 1. Dimensionless energy density for the mechanisms examined in this review.

\begin{tabular}{ccc}
\hline Field Type & $\boldsymbol{\Lambda}^{\mathbf{1}}$ & References \\
\hline Electric & $\pi \varepsilon_{m} a^{3}\left(f_{c m} E_{o}\right)^{2} / k_{B} T$ & {$[85,202,203]$} \\
\hline Magnetic & $\pi \mu_{o} a^{3}\left[\left(\chi_{p}-\chi_{m}\right) H\right]^{2} / 9 k_{B} T$ & {$[95,204,205]$} \\
\hline Acoustic & $V_{p} \Phi^{2} E_{a c} / 2 k_{B} T$ & {$[206-208]^{2}$} \\
\hline
\end{tabular}

${ }_{1}^{1}$ The dimensionless energy density is scaled by, $k_{B}$, Boltzmann's constant and the ambient temperature, $T$. ${ }^{2} E_{a c}=P_{0}^{2} / 4 \rho_{m} c_{m}^{2}$ is the acoustic energy density. The one-half factor comes from the fact that $E_{a c}$ represents the full oscillation range for the acoustic field. Thus, $E_{a c} / 2$ represents the acoustic field energy density magnitude.

To qualitatively see how RDF impacts mechanical properties, consider the cases of parallel $\left(\|, \theta=0^{\circ}\right)$ alignment:

$$
\chi_{\|} \approx \chi_{h s} \exp (\Lambda),
$$

Thus, we can see that parallel alignment has a strong effect on RDF. According to Baxter-Drayton and Brady [200], the RDF at contact for an aligned system saturates at high values of $\Lambda$, limiting $\chi_{\|}$to a maximum value of $\sim 240$. Qualitatively, based on Equation (16), this translates to a larger elastic modulus in the direction of alignment. We combined Equations (16) and (18) to produce Figure 8, which shows how RDF impacts Young's modulus value. A combination of field strength, measured by $\Lambda$, and volume fraction, potentially, can increase Young's modulus $\left(E_{0}\right)$ by as much as 6000 times that of bare polymer. To illustrate the significance of this, consider that a polymeric material, such as PDMS, has a Young's modulus of $\sim 2 \mathrm{MPa}$ [209]. The inclusion of field aligned particles could increase the elastic modulus of PDMS to a value of $\sim 12 \mathrm{GPa}$, which is comparable to bone, concrete, or certain types of wood. Overall, the connection between particle distribution vis-à-vis RDF and mechanical properties serves as another possible avenue for future research. While the model presented above suggests a connection to mechanical properties, it would also be useful to explore how RDF impacts other particle-polymer composite properties, such as thermal [210-212] or electrical [213-215] conductivity. 


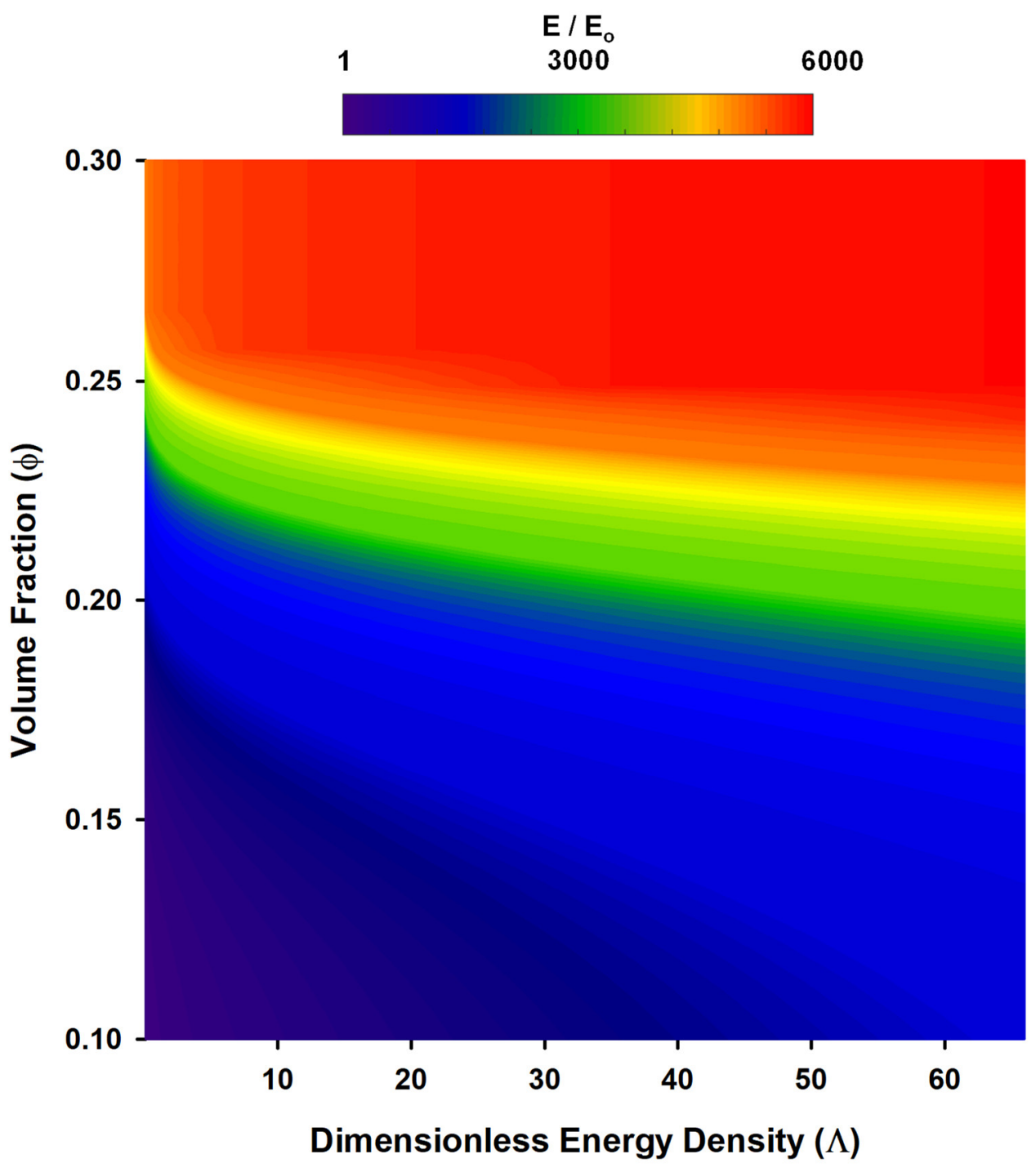

Figure 8. A contour plot of normalized Young's modulus (Equation (16)) illustrating the impact that filler particle volume fraction and the dimensionless energy density of an applied external field have on mechanical properties. The field influences the RDF of the filler particles (Equation (18)), which also influences Young's modulus as described by Equation (16).

Models of particle behavior during the AM process could lead to process control techniques that affect field conditions (e.g., amplitude and frequency) $[74,216,217]$, particle type [218-220], and shear stress [221-223]. A fundamental understanding obtained through modeling would be a pathway towards achieving specific microstructures with targeted properties. Such process control strategies could be developed using real-time field actuation to direct particle assembly [224-226], gain-scheduling policies that maximize particle packing [227-229], or the identification of an open-loop strategy that would achieve a desired order parameter, such as the degree of hexagonal close-packing [230,231].

Applying external fields to AM of particle-polymer composites provides a unique approach to functionally structure these composites by internally aligning the particles. This would create opportunities to fabricate these composites for targeted mechanical, thermal, electrical, or optical applications. However, it is necessary to improve our fundamental understanding of the AM process in the presence of an external field and how composite processing impacts its material properties. Process control for directed assembly-based $\mathrm{AM}$ is an area of research that requires further exploration. Challenges associated with this line of research include identifying the appropriate transport mechanism for a given 
polymer/particle system to use as an actuator, developing sensing techniques that could be used to guide the assembly process in real time, and connecting the composite properties to match desired material properties.

Author Contributions: Conceptualization, S.S. and J.J.J.; resources, J.J.J.; data curation, S.S. and J.J.J.; writing—original draft preparation, S.S.; writing—review and editing, J.J.J.; supervision, J.J.J.; project administration, J.J.J.; funding acquisition, J.J.J. All authors have read and agreed to the published version of the manuscript.

Funding: This research was funded by the Iowa State Microelectronics Research Center Catron Fellowship. The APC was funded by the Iowa State University Open Access Subvention Grant and the National Science Foundation, grant number 2050105.

Institutional Review Board Statement: Not applicable.

Informed Consent Statement: Not applicable.

Data Availability Statement: All data provided in the present manuscript are available to whom it may concern.

Conflicts of Interest: The authors declare no conflict of interest.

\section{References}

1. Gibson, I.; Rosen, D.W.; Stucker, B. Design for Additive Manufacturing. In Additive Manufacturing Technologies: Rapid Prototyping to Direct Digital Manufacturing; Gibson, I., Rosen, D.W., Stucker, B., Eds.; Springer US: Boston, MA, USA, 2010 ; pp. $299-332$. ISBN 978-1-4419-1120-9.

2. Wohlers Associates. Wohlers Report 2016: 3D Printing and Additive Manufacturing State of the Industry: Annual Worldwide Progress Report; Wohlers Associates: Fort Collins, CO, USA, 2016; ISBN 978-0-9913332-2-6.

3. Wong, K.V.; Hernandez, A. A Review of Additive Manufacturing. Available online: https://www.hindawi.com/journals/isrn/ 2012/208760/ (accessed on 6 February 2019).

4. Dizon, J.R.C.; Espera, A.H.; Chen, Q.; Advincula, R.C. Mechanical characterization of 3D-printed polymers. Addit. Manuf. 2018, 20, 44-67. [CrossRef]

5. National Research Council (U.S.). Polymer Science and Engineering: The Shifting Research Frontiers; National Academy Press: Washington, DC, USA, 1994; ISBN 978-0-309-04998-6.

6. Siegel, J.E.; Erb, D.C.; Ehrenberg, I.M.; Jain, P.; Sarma, S.E. Local Viscosity Control Printing for High-Throughput Additive Manufacturing of Polymers. 3D Print. Addit. Manuf. 2016, 3, 252-261. [CrossRef]

7. Mackay, M.E. The importance of rheological behavior in the additive manufacturing technique material extrusion. J. Rheol. 2018, 62, 1549-1561. [CrossRef]

8. Cicala, G.; Giordano, D.; Tosto, C.; Filippone, G.; Recca, A.; Blanco, I. Polylactide (PLA) Filaments a Biobased Solution for Additive Manufacturing: Correlating Rheology and Thermomechanical Properties with Printing Quality. Materials 2018, $11,1191$. [CrossRef] [PubMed]

9. Schultz, A.R.; Lambert, P.M.; Chartrain, N.A.; Ruohoniemi, D.M.; Zhang, Z.; Jangu, C.; Zhang, M.; Williams, C.B.; Long, T.E. 3D Printing Phosphonium Ionic Liquid Networks with Mask Projection Microstereolithography. ACS Macro Lett. 2014 , 3, $1205-1209$. [CrossRef]

10. Karjalainen, E.; Wales, D.J.; Gunasekera, D.H.A.T.; Dupont, J.; Licence, P.; Wildman, R.D.; Sans, V. Tunable Ionic Control of Polymeric Films for Inkjet Based 3D Printing. ACS Sustain. Chem. Eng. 2018, 6, 3984-3991. [CrossRef]

11. Nulwala, H.; Mirjafari, A.; Zhou, X. Ionic liquids and poly(ionic liquid)s for 3D printing-A focused mini-review. Eur. Polym. J. 2018, 108, 390-398. [CrossRef]

12. Maciel, V.G.; Wales, D.J.; Seferin, M.; Sans, V. Environmental performance of 3D-Printing polymerisable ionic liquids. J. Clean. Prod. 2019, 214, 29-40. [CrossRef]

13. Bakarich, S.E.; Gorkin, R.; in het Panhuis, M.I.; Spinks, G.M. 4D Printing with Mechanically Robust, Thermally Actuating Hydrogels. Macromol. Rapid Commun. 2015, 36, 1211-1217. [CrossRef]

14. Zhao, Q.; Zou, W.; Luo, Y.; Xie, T. Shape memory polymer network with thermally distinct elasticity and plasticity. Sci. Adv. 2016, 2, e1501297. [CrossRef]

15. Kalsoom, U.; Peristyy, A.; Nesterenko, P.N.; Paull, B. A 3D printable diamond polymer composite: A novel material for fabrication of low cost thermally conducting devices. RSC Adv. 2016, 6, 38140-38147. [CrossRef]

16. Xia, H.; Wang, J.; Tian, Y.; Chen, Q.-D.; Du, X.-B.; Zhang, Y.-L.; He, Y.; Sun, H.-B. Ferrofluids for Fabrication of Remotely Controllable Micro-Nanomachines by Two-Photon Polymerization. Adv. Mater. 2010, 22, 3204-3207. [CrossRef] [PubMed]

17. Kokkinis, D.; Schaffner, M.; Studart, A.R. Multimaterial Magnetically Assisted 3D Printing of Composite Materials. Nat. Commun. 2015, 6, 8643. [CrossRef] [PubMed] 
18. Huber, C.; Abert, C.; Bruckner, F.; Groenefeld, M.; Muthsam, O.; Schuschnigg, S.; Sirak, K.; Thanhoffer, R.; Teliban, I.; Vogler, C.; et al. 3D print of polymer bonded rare-earth magnets, and 3D magnetic field scanning with an end-user 3D printer. Appl. Phys. Lett. 2016, 109, 162401. [CrossRef]

19. Castles, F.; Isakov, D.; Lui, A.; Lei, Q.; Dancer, C.E.J.; Wang, Y.; Janurudin, J.M.; Speller, S.C.; Grovenor, C.R.M.; Grant, P.S. Microwave dielectric characterisation of 3D-printed $\mathrm{BaTiO}_{3} / \mathrm{ABS}$ polymer composites. Sci. Rep. 2016, 6, 22714. [CrossRef]

20. Yang, Y.; Chen, Z.; Song, X.; Zhu, B.; Hsiai, T.; Wu, P.-I.; Xiong, R.; Shi, J.; Chen, Y.; Zhou, Q.; et al. Three dimensional printing of high dielectric capacitor using projection based stereolithography method. Nano Energy 2016, 22, 414-421. [CrossRef]

21. Zhang, S.; Njoku, C.C.; Whittow, W.G.; Vardaxoglou, J.C. Novel 3D printed synthetic dielectric substrates. Microw. Opt. Technol. Lett. 2015, 57, 2344-2346. [CrossRef]

22. Debelak, B.; Lafdi, K. Use of exfoliated graphite filler to enhance polymer physical properties. Carbon 2007, 45, 1727-1734. [CrossRef]

23. Colombo, P.; Bernardo, E.; Parcianello, G. Multifunctional advanced ceramics from preceramic polymers and nano-sized active fillers. J. Eur. Ceram. Soc. 2013, 33, 453-469. [CrossRef]

24. de Leon, A.C.; Chen, Q.; Palaganas, N.B.; Palaganas, J.O.; Manapat, J.; Advincula, R.C. High performance polymer nanocomposites for additive manufacturing applications. React. Funct. Polym. 2016, 103, 141-155. [CrossRef]

25. Stansbury, J.W.; Idacavage, M.J. 3D printing with polymers: Challenges among expanding options and opportunities. Dent. Mater. 2016, 32, 54-64. [CrossRef]

26. Lebedev, S.M.; Gefle, O.S.; Amitov, E.T.; Berchuk, D.Y.; Zhuravlev, D.V. Poly(lactic acid)-based polymer composites with high electric and thermal conductivity and their characterization. Polym. Test. 2017, 58, 241-248. [CrossRef]

27. Kang, E.; Jeong, G.S.; Choi, Y.Y.; Lee, K.H.; Khademhosseini, A.; Lee, S.-H. Digitally tunable physicochemical coding of material composition and topography in continuous microfibres. Nat. Mater. 2011, 10, 877-883. [CrossRef] [PubMed]

28. Liu, W.; Zhang, Y.S.; Heinrich, M.A.; De Ferrari, F.; Jang, H.L.; Bakht, S.M.; Alvarez, M.M.; Yang, J.; Li, Y.-C.; Trujillo-de Santiago, G.; et al. Rapid Continuous Multimaterial Extrusion Bioprinting. Adv. Mater. 2017, 29, 1604630. [CrossRef]

29. Chung, D.D.L. A review of multifunctional polymer-matrix structural composites. Compos. Part B Eng. 2019, 160, 644-660. [CrossRef]

30. Vaezi, M.; Chianrabutra, S.; Mellor, B.; Yang, S. Multiple material additive manufacturing-Part 1: A review. Virtual Phys. Prototyp. 2013, 8, 19-50. [CrossRef]

31. Ge, Q.; Sakhaei, A.H.; Lee, H.; Dunn, C.K.; Fang, N.X.; Dunn, M.L. Multimaterial 4D Printing with Tailorable Shape Memory Polymers. Sci. Rep. 2016, 6, 31110. [CrossRef] [PubMed]

32. Bandyopadhyay, A.; Heer, B. Additive manufacturing of multi-material structures. Mater. Sci. Eng. R: Rep. 2018, 129, 1-16. [CrossRef]

33. Tsai, P.J.; Ghosh, S.; Wu, P.; Puri, I.K. Tailoring Material Stiffness by Filler Particle Organization. ACS Appl. Mater. Interfaces 2016, 8, 27449-27453. [CrossRef] [PubMed]

34. Holmes, L.R.; Riddick, J.C. Research Summary of an Additive Manufacturing Technology for the Fabrication of 3D Composites with Tailored Internal Structure. JOM 2014, 66, 270-274. [CrossRef]

35. Varga, Z.; Filipcsei, G.; Zrínyi, M. Magnetic field sensitive functional elastomers with tuneable elastic modulus. Polymer 2006, 47, 227-233. [CrossRef]

36. Sorrentino, L.; Aurilia, M.; Forte, G.; Iannace, S. Anisotropic mechanical behavior of magnetically oriented iron particle reinforced foams. J. Appl. Polym. Sci. 2011, 119, 1239-1247. [CrossRef]

37. Song, P.; Peng, Z.-J.; Yue, Y.-L.; Zhang, H.; Zhang, Z.; Fan, Y.-C. Mechanical properties of silicone composites reinforced with micron- and nano-sized magnetic particles. Express Polym. Lett. 2013, 7, 546-553. [CrossRef]

38. Compton, B.G.; Lewis, J.A. 3D-Printing of Lightweight Cellular Composites. Adv. Mater. 2014, 26, 5930-5935. [CrossRef] [PubMed]

39. Kimura, T.; Ago, H.; Tobita, M.; Ohshima, S.; Kyotani, M.; Yumura, M. Polymer Composites of Carbon Nanotubes Aligned by a Magnetic Field. Adv. Mater. 2002, 14, 1380-1383. [CrossRef]

40. Filipcsei, G.; Csetneki, I.; Szilágyi, A.; Zrínyi, M. Magnetic Field-Responsive Smart Polymer Composites. In Oligomers—Polymer Composites-Molecular Imprinting; Advances in Polymer Science; Springer: Berlin/Heidelberg, Germany, 2007; pp. 137-189. ISBN 9783540468295.

41. Tomer, V.; Randall, C.A.; Polizos, G.; Kostelnick, J.; Manias, E. High- and low-field dielectric characteristics of dielectrophoretically aligned ceramic/polymer nanocomposites. J. Appl. Phys. 2008, 103, 034115. [CrossRef]

42. Tanimoto, M.; Yamagata, T.; Miyata, K.; Ando, S. Anisotropic Thermal Diffusivity of Hexagonal Boron Nitride-Filled Polyimide Films: Effects of Filler Particle Size, Aggregation, Orientation, and Polymer Chain Rigidity. ACS Appl. Mater. Interfaces 2013, 5 , 4374-4382. [CrossRef] [PubMed]

43. Lipomi, D.J.; Vosgueritchian, M.; Tee, B.C.-K.; Hellstrom, S.L.; Lee, J.A.; Fox, C.H.; Bao, Z. Skin-like pressure and strain sensors based on transparent elastic films of carbon nanotubes. Nat. Nanotechnol. 2011, 6, 788-792. [CrossRef] [PubMed]

44. Lee, S.; Shin, S.; Lee, S.; Seo, J.; Lee, J.; Son, S.; Cho, H.J.; Algadi, H.; Al-Sayari, S.; Kim, D.E.; et al. Ag Nanowire Reinforced Highly Stretchable Conductive Fibers for Wearable Electronics. Adv. Funct. Mater. 2015, 25, 3114-3121. [CrossRef]

45. Lv, T.; Yao, Y.; Li, N.; Chen, T. Wearable fiber-shaped energy conversion and storage devices based on aligned carbon nanotubes. Nano Today 2016, 11, 644-660. [CrossRef] 
46. Weng, W.; Sun, Q.; Zhang, Y.; Lin, H.; Ren, J.; Lu, X.; Wang, M.; Peng, H. Winding Aligned Carbon Nanotube Composite Yarns into Coaxial Fiber Full Batteries with High Performances. Nano Lett. 2014, 14, 3432-3438. [CrossRef]

47. Zhang, M.; Gao, T.; Wang, J.; Liao, J.; Qiu, Y.; Xue, H.; Shi, Z.; Xiong, Z.; Chen, L. Single BaTiO3 nanowires-polymer fiber based nanogenerator. Nano Energy 2015, 11, 510-517. [CrossRef]

48. Pan, S.; Lin, H.; Deng, J.; Chen, P.; Chen, X.; Yang, Z.; Peng, H. Novel Wearable Energy Devices Based on Aligned Carbon Nanotube Fiber Textiles. Adv. Energy Mater. 2015, 5, 1401438. [CrossRef]

49. Martin, J.E.; Anderson, R.A. Electrostriction in field-structured composites: Basis for a fast artificial muscle? J. Chem. Phys. 1999, 111, 4273-4280. [CrossRef]

50. Mirfakhrai, T.; Madden, J.D.W.; Baughman, R.H. Polymer artificial muscles. Mater. Today 2007, 10, 30-38. [CrossRef]

51. Chun, K.-Y.; Hyeong Kim, S.; Kyoon Shin, M.; Hoon Kwon, C.; Park, J.; Tae Kim, Y.; Spinks, G.M.; Lima, M.D.; Haines, C.S.; Baughman, R.H.; et al. Hybrid carbon nanotube yarn artificial muscle inspired by spider dragline silk. Nat. Commun. 2014, 5, 3322. [CrossRef] [PubMed]

52. Morales, D.; Bharti, B.; Dickey, M.D.; Velev, O.D. Bending of Responsive Hydrogel Sheets Guided by Field-Assembled Microparticle Endoskeleton Structures. Small 2016, 12, 2283-2290. [CrossRef] [PubMed]

53. Schmauch, M.M.; Mishra, S.R.; Evans, B.A.; Velev, O.D.; Tracy, J.B. Chained Iron Microparticles for Directionally Controlled Actuation of Soft Robots. ACS Appl. Mater. Interfaces 2017, 9, 11895-11901. [CrossRef]

54. Tognato, R.; Armiento, A.R.; Bonfrate, V.; Levato, R.; Malda, J.; Alini, M.; Eglin, D.; Giancane, G.; Serra, T. A Stimuli-Responsive Nanocomposite for 3D Anisotropic Cell-Guidance and Magnetic Soft Robotics. Adv. Funct. Mater. 2019, 29, 1804647. [CrossRef]

55. Fu, M.; Chaudhary, K.; Lange, J.G.; Kim, H.S.; Juárez, J.J.; Lewis, J.A.; Braun, P.V. Anisotropic Colloidal Templating of 3D Ceramic, Semiconducting, Metallic, and Polymeric Architectures. Adv. Mater. 2014, 26, 1740-1745. [CrossRef]

56. Wang, H.; Zhang, H.; Zhao, W.; Zhang, W.; Chen, G. Preparation of polymer/oriented graphite nanosheet composite by electric field-inducement. Compos. Sci. Technol. 2008, 68, 238-243. [CrossRef]

57. Fragouli, D.; Buonsanti, R.; Bertoni, G.; Sangregorio, C.; Innocenti, C.; Falqui, A.; Gatteschi, D.; Cozzoli, P.D.; Athanassiou, A.; Cingolani, R. Dynamical Formation of Spatially Localized Arrays of Aligned Nanowires in Plastic Films with Magnetic Anisotropy. ACS Nano 2010, 4, 1873-1878. [CrossRef]

58. Erb, R.M.; Libanori, R.; Rothfuchs, N.; Studart, A.R. Composites Reinforced in Three Dimensions by Using Low Magnetic Fields. Science 2012, 335, 199-204. [CrossRef] [PubMed]

59. Scholz, M.-S.; Drinkwater, B.W.; Trask, R.S. Ultrasonic assembly of anisotropic short fibre reinforced composites. Ultrasonics 2014, 54, 1015-1019. [CrossRef] [PubMed]

60. Shabaniverki, S.; Thorud, S.; Juárez, J.J. Vibrationally directed assembly of micro- and nanoparticle-polymer composites. Chem. Eng. Sci. 2018, 192, 1209-1217. [CrossRef]

61. Akella, M.; Juárez, J.J. High-Throughput Acoustofluidic Self-Assembly of Colloidal Crystals. ACS Omega 2018, 3, 1425-1436. [CrossRef] [PubMed]

62. O'Brien, R.W. Electro-acoustic effects in a dilute suspension of spherical-particles. J. Fluid Mech. 1988, 190, 71-86. [CrossRef]

63. Bahukudumbi, P.; Everett, W.N.; Beskok, A.; Bevan, M.A.; Huff, G.H.; Lagoudas, D.; Ounaies, Z. Colloidal microstructures, transport, and impedance properties within interfacial microelectrodes. Appl. Phys. Lett. 2007, 90, 224102-224103. [CrossRef]

64. Ammam, M. Electrophoretic deposition under modulated electric fields: A review. RSC Adv. 2012, 2, 7633-7647. [CrossRef]

65. Neirinck, B.; Van Der Biest, O.; Vleugels, J. A Current Opinion on Electrophoretic Deposition in Pulsed and Alternating Fields. J. Phys. Chem. B 2013, 117, 1516-1526. [CrossRef]

66. Wu, K.; Imin, P.; Adronov, A.; Zhitomirsky, I. Electrophoretic deposition of poly [3 -(3-N,N-diethylaminopropoxy)thiophene] and composite films. Mater. Chem. Phys. 2011, 125, 210-218. [CrossRef]

67. Yang, L.; Pang, X.; Fox-Rabinovich, G.; Veldhuis, S.; Zhitomirsky, I. Electrophoretic deposition of polymer and composite films. Surf. Eng. 2012, 28, 585-589. [CrossRef]

68. Sun, Y.; Ata, M.S.; Zhitomirsky, I. Electrophoretic deposition of linear polyethylenimine and composite films. Surf. Eng. 2013, 29, 495-499. [CrossRef]

69. Itoh, E.; Suzuki, I.; Miyairi, K. Field Emission from Carbon-Nanotube-Dispersed Conducting Polymer Thin Film and Its Application to Photovoltaic Devices. Jpn. J. Appl. Phys. 2005, 44, 636. [CrossRef]

70. An, Q.; Rider, A.N.; Thostenson, E.T. Hierarchical Composite Structures Prepared by Electrophoretic Deposition of Carbon Nanotubes onto Glass Fibers. ACS Appl. Mater. Interfaces 2013, 5, 2022-2032. [CrossRef] [PubMed]

71. Yang, Z.; Wang, H.; Zhang, Z.; Ding, G.; Zhao, X. Microtensile test of an ordered-reinforced electrophoretic polymer matrix composite fabricated by surface micromachining. Surf. Rev. Lett. 2011, 18, 169-175. [CrossRef]

72. Morgan, H.; Green, N.G. AC Electrokinetic: Colloids and Nanoparticles, 1st ed.; Research Studies Pr: Philadelphia, PA, USA, 2002; ISBN 978-0-86380-255-3.

73. Juárez, J.J.; Cui, J.-Q.; Liu, B.G.; Bevan, M.A. kT-Scale Colloidal Interactions in High Frequency Inhomogeneous AC Electric Fields. I. Single Particles. Langmuir 2011, 27, 9211-9218. [CrossRef] [PubMed]

74. Juárez, J.J.; Liu, B.G.; Cui, J.-Q.; Bevan, M.A. kT-Scale Colloidal Interactions in High-Frequency Inhomogeneous AC Electric Fields. II. Concentrated Ensembles. Langmuir 2011, 27, 9219-9226. [CrossRef]

75. Pethig, R. Dielectrophoresis: Status of the Theory, Technology, and Applications. Biomicrofluidics 2010, 4, 022811. [CrossRef] [PubMed] 
76. Jones, T.B. Electromechanics of Particles; Cambridge University Press: Cambridge, UK, 1995; ISBN 0521431964.

77. Adriani, P.M.; Gast, A.P. A microscopic model of electrorheology. Phys. Fluids 1988, 31, 2757-2768. [CrossRef]

78. Whittle, M. Computer simulation of an electrorheological fluid. J. Non-Newton. Fluid Mech. 1990, 37, 233-263. [CrossRef]

79. Li, X.; Cai, J.; Shi, Y.; Yue, Y.; Zhang, D. Remarkable Conductive Anisotropy of Metallic Microcoil/PDMS Composites Made by Electric Field Induced Alignment. ACS Appl. Mater. Interfaces 2017, 9, 1593-1601. [CrossRef]

80. Knaapila, M.; Høyer, H.; Svåsand, E.; Buchanan, M.; Skjeltorp, A.T.; Helgesen, G. Aligned carbon cones in free-standing UV-Curable polymer composite. J. Polym. Sci. Part B Polym. Phys. 2011, 49, 399-403. [CrossRef]

81. Liu, X.; Liu, J.; Guo, Y.; Cakmak, M. Electric field assisted gradient structure formation of glass microsphere columns in polymer films. Compos. Sci. Technol. 2017, 153, 62-70. [CrossRef]

82. Sengezer, E.C.; Seidel, G.D.; Bodnar, R.J. Phenomenological characterization of fabrication of aligned pristine-SWNT and COOH-SWNT nanocomposites via dielectrophoresis under AC electric field. Polym. Compos. 2015, 36, 1266-1279. [CrossRef]

83. Høyer, H.; Knaapila, M.; Kjelstrup-Hansen, J.; Liu, X.; Helgesen, G. Individual strings of conducting carbon cones and discs in a polymer matrix: Electric field-induced alignment and their use as a strain sensor. J. Polym. Sci. Part B Polym. Phys. 2012, 50, 477-483. [CrossRef]

84. Lai, Y.-T.; Chen, Y.-M.; Yang, Y.-J.J. A Novel CNT-PDMS-Based Tactile Sensing Array With Resistivity Retaining and Recovering by Using Dielectrophoresis Effect. J. Microelectromech. Syst. 2011, 21, 217-223. [CrossRef]

85. Juárez, J.J.; Bevan, M.A. Interactions and microstructures in electric field mediated colloidal assembly. J. Chem. Phys. 2009, 131, 134704. [CrossRef]

86. Belijar, G.; Valdez-Nava, Z.; Diaham, S.; Laudebat, L.; Jones, T.B.; Lebey, T. Dynamics of particle chain formation in a liquid polymer under ac electric field: Modeling and experiments. J. Phys. D Appl. Phys. 2016, 50, 025303. [CrossRef]

87. Batra, S.; Cakmak, M. Ultra-capacitor flexible films with tailored dielectric constants using electric field assisted assembly of nanoparticles. Nanoscale 2015, 7, 20571-20583. [CrossRef]

88. Kim, G.; Shkel, Y.M. Analysis of the electro-orientation of inorganic micro/nano-particles in a liquid polymer considering electrophoresis flow. J. Micromech. Microeng. 2007, 17, 2522-2527. [CrossRef]

89. Oliva-Avilés, A.I.; Alonzo-García, A.; Zozulya, V.V.; Gamboa, F.; Cob, J.; Avilés, F. A dielectrophoretic study of the carbon nanotube chaining process and its dependence on the local electric fields. Meccanica 2018, 53, 2773-2791. [CrossRef]

90. Sengezer, E.C.; Seidel, G.D.; Bodnar, R.J. Anisotropic piezoresistivity characteristics of aligned carbon nanotube-polymer nanocomposites. Smart Mater. Struct. 2017, 26, 095027. [CrossRef]

91. Liu, Z.; Peng, P.; Liu, Z.; Fang, W.; Zhou, Q.; Liu, X.; Liu, J. Electric-field-induced out-of-plane alignment of clay in poly(dimethylsiloxane) with enhanced anisotropic thermal conductivity and mechanical properties. Compos. Sci. Technol. 2018, 165, 39-47. [CrossRef]

92. Ji, T.; Feng, Y.; Qin, M.; Li, S.; Zhang, F.; Lv, F.; Feng, W. Thermal conductive and flexible silastic composite based on a hierarchical framework of aligned carbon fibers-carbon nanotubes. Carbon 2018, 131, 149-159. [CrossRef]

93. Pethig, R.R. Dielectrophoresis: Theory, Methodology and Biological Applications, 1st ed.; Wiley: Hoboken, NJ, USA, 2017.

94. McHenry, M.E.; Laughlin, D.E. Magnetic Moment and Magnetization. In Characterization of Materials; Wiley: Hoboken, NJ, USA, 2012; pp. 1-25, ISBN 9780471266969.

95. Furst, E.M.; Gast, A.P. Micromechanics of magnetorheological suspensions. Phys. Rev. E 2000, 61, 6732. [CrossRef]

96. Ji, D.; Luo, Y.; Ren, H.; Wei, D.; Shao, J. Numerical Simulation and Experimental Analysis of Microstructure of Magnetorheological Fluid. J. Nanomater. 2019, 2019, 6312606. [CrossRef]

97. Ginder, J.M.; Nichols, M.E.; Elie, L.D.; Tardiff, J.L. Magnetorheological elastomers: Properties and applications. In Smart Structures and Materials: Smart Materials Technologies; International Society for Optics and Photonics: Bellingham, WA, USA, 1999; Volume 3675, pp. 131-138.

98. Jolly, M.R.; Bender, J.W.; Carlson, J.D. Properties and Applications of Commercial Magnetorheological Fluids. J. Intell. Mater. Syst. Struct. 1999, 10, 5-13. [CrossRef]

99. Sauzedde, F.; Elaïssari, A.; Pichot, C. Hydrophilic magnetic polymer latexes. Adsorption of magnetic iron oxide nanoparticles onto various cationic latexes. Colloid Polym. Sci. 1999, 277, 846-855. [CrossRef]

100. Shiga, T.; Okada, A.; Kurauchi, T. Magnetroviscoelastic behavior of composite gels. J. Appl. Polym. Sci. 1995, 58, 787-792. [CrossRef]

101. Shiga, T.; Okada, A.; Kurauchi, T. Electroviscoelastic effect of polymer blends consisting of silicone elastomer and semiconducting polymer particles. Macromolecules 1993, 26, 6958-6963. [CrossRef]

102. Zrínyi, M.; Barsi, L.; Büki, A. Deformation of ferrogels induced by nonuniform magnetic fields. J. Chem. Phys. 1996, 104, 8750-8756. [CrossRef]

103. Zrinyi, M.; Barsi, L.; Szabó, D.; Kilian, H.-G. Direct observation of abrupt shape transition in ferrogels induced by nonuniform magnetic field. J. Chem. Phys. 1997, 106, 5685-5692. [CrossRef]

104. Shabaniverki, S.; Xie, S.; Ren, J.; Juárez, J.J. Soft Ferrofluid Actuator Based on 3D-Printed Scaffold Removal. 3D Print. Addit. Manuf. 2021, 8, 126-135. [CrossRef]

105. Snyder, R.L.; Nguyen, V.Q.; Ramanujan, R.V. Design parameters for magneto-elastic soft actuators. Smart Mater. Struct. 2010, 19, 055017. [CrossRef]

106. Zrínyi, M. Intelligent polymer gels controlled by magnetic fields. Colloid Polym. Sci. 2000, 278, 98-103. [CrossRef] 
107. Hatzfeld, C.; Bilz, J.; Fritzsche, T.; Kupnik, M. A Reconfigurable Haptic Joystick Based on Magneto-Rheological ElastomersSystem Design and First Evaluation. In Haptics: Perception, Devices, Control, and Applications; Bello, F., Kajimoto, H., Visell, Y., Eds.; Springer International Publishing: London, UK, 2016; pp. 109-119.

108. Wu, W.; He, Q.; Jiang, C. Magnetic Iron Oxide Nanoparticles: Synthesis and Surface Functionalization Strategies. Nanoscale Res. Lett. 2008, 3, 397-415. [CrossRef]

109. Ghosh, S.; Puri, I.K. Soft polymer magnetic nanocomposites: Microstructure patterning by magnetophoretic transport and self-assembly. Soft Matter 2013, 9, 2024-2029. [CrossRef] [PubMed]

110. Dhar, P.; Kumar, A.; Katiyar, V. Magnetic Cellulose Nanocrystal Based Anisotropic Polylactic Acid Nanocomposite Films: Influence on Electrical, Magnetic, Thermal, and Mechanical Properties. ACS Appl. Mater. Interfaces 2016, 8, 18393-18409. [CrossRef] [PubMed]

111. Kwon, S.H.; Lee, C.J.; Choi, H.J.; Chung, K.H.; Jung, J.H. Viscoelastic and mechanical behaviors of magneto-rheological carbonyl iron/natural rubber composites with magnetic iron oxide nanoparticle. Smart Mater. Struct. 2019, 28, 045012. [CrossRef]

112. Cao, L.; Cheng, Z.; Yan, M.; Chen, Y. Anisotropic rubber nanocomposites via magnetic-induced alignment of Fe3O4/cellulose nanocrystals hybrids obtained by templated assembly. Chem. Eng. J. 2019, 363, 203-212. [CrossRef]

113. Goldberg, O.; Greenfeld, I.; Wagner, H.D. Composite Reinforcement by Magnetic Control of Fiber Density and Orientation. ACS Appl. Mater. Interfaces 2018, 10, 16802-16811. [CrossRef] [PubMed]

114. Al-Haik, M.S.; Garmestani, H.; Li, D.S.; Hussaini, M.Y.; Sablin, S.S.; Tannenbaum, R.; Dahmen, K. Mechanical properties of magnetically oriented epoxy. J. Polym. Sci. Part B Polym. Phys. 2004, 42, 1586-1600. [CrossRef]

115. Yang, Z.; Wei, J.; Gizynski, K.; Song, M.-G.; Grzybowski, B.A. Interference-like patterns of static magnetic fields imprinted into polymer/nanoparticle composites. Nat. Commun. 2017, 8, 1564. [CrossRef] [PubMed]

116. Garmestani, H.; Al-Haik, M.S.; Dahmen, K.; Tannenbaum, R.; Li, D.; Sablin, S.S.; Hussaini, M.Y. Polymer-Mediated Alignment of Carbon Nanotubes under High Magnetic Fields. Adv. Mater. 2003, 15, 1918-1921. [CrossRef]

117. Goh, P.S.; Ismail, A.F.; Ng, B.C. Directional alignment of carbon nanotubes in polymer matrices: Contemporary approaches and future advances. Compos. Part A Appl. Sci. Manuf. 2014, 56, 103-126. [CrossRef]

118. Wu, S.; Peng, S.; Wang, C.H. Multifunctional Polymer Nanocomposites Reinforced by Aligned Carbon Nanomaterials. Polymers (Basel) 2018, 10, 542. [CrossRef]

119. Ranzoni, A.; Janssen, X.J.A.; Ovsyanko, M.; Van Ijzendoorn, L.J.; Prins, M.W.J. Magnetically controlled rotation and torque of uniaxial microactuators for lab-on-a-chip applications. Lab Chip 2009, 10, 179-188. [CrossRef]

120. Camponeschi, E.; Vance, R.; Al-Haik, M.; Garmestani, H.; Tannenbaum, R. Properties of carbon nanotube-polymer composites aligned in a magnetic field. Carbon 2007, 45, 2037-2046. [CrossRef]

121. Huang, Y.; Jiao, W.; Niu, Y.; Ding, G.; Wang, R. Improving the mechanical properties of Fe3O4/carbon nanotube reinforced nanocomposites by a low-magnetic-field induced alignment. J. Polym. Eng. 2018, 38, 731-738. [CrossRef]

122. Kumar, V.; Lee, D.-J. Mechanical properties and magnetic effect of new magneto-rheological elastomers filled with multi-wall carbon nanotubes and iron particles. J. Magn. Magn. Mater. 2019, 482, 329-335. [CrossRef]

123. He, Y.; Yang, S.; Liu, H.; Shao, Q.; Chen, Q.; Lu, C.; Jiang, Y.; Liu, C.; Guo, Z. Reinforced carbon fiber laminates with oriented carbon nanotube epoxy nanocomposites: Magnetic field assisted alignment and cryogenic temperature mechanical properties. $J$. Colloid Interface Sci. 2018, 517, 40-51. [CrossRef]

124. Liu, M.; Younes, H.; Hong, H.; Peterson, G.P. Polymer nanocomposites with improved mechanical and thermal properties by magnetically aligned carbon nanotubes. Polymer 2019, 166, 81-87. [CrossRef]

125. Malkina, O.; Mahfuz, H.; Sorge, K.; Rondinone, A.; Chen, J.; More, K.; Reeves, S.; Rangari, V. Magnetic alignment of SWCNTs decorated with Fe3O4 to enhance mechanical properties of SC-15 epoxy. AIP Adv. 2013, 3, 042104. [CrossRef]

126. Chen, Y.-F.; Li, J.; Tan, Y.-J.; Zhang, K.; Shi, Y.-D.; Wu, H.; Guo, S.; Wang, M. Low magnetic field-induced morphological regulation in isotactic polypropylene/poly( $\varepsilon$-caprolactone)/carbon black composites for high electrical conductivity and conductive anisotropy. Compos. Commun. 2018, 9, 58-62. [CrossRef]

127. Prolongo, S.G.; Meliton, B.G.; Del Rosario, G.; Ureña, A. New alignment procedure of magnetite-CNT hybrid nanofillers on epoxy bulk resin with permanent magnets. Compos. Part B Eng. 2013, 46, 166-172. [CrossRef]

128. Tanabi, H.; Erdal, M. Effect of CNTs dispersion on electrical, mechanical and strain sensing properties of CNT/epoxy nanocomposites. Results Phys. 2019, 12, 486-503. [CrossRef]

129. Gaska, K.; Kmita, G.; Rybak, A.; Sekula, R.; Goc, K.; Kapusta, C. Magnetic-aligned, magnetite-filled epoxy composites with enhanced thermal conductivity. J. Mater. Sci. 2015, 50, 2510-2516. [CrossRef]

130. Sun, M.; Dai, B.; Liu, K.; Yao, K.; Zhao, J.; Lyu, Z.; Wang, P.; Ding, Y.; Yang, L.; Han, J.; et al. Enhancement in thermal conductivity of polymer composites using aligned diamonds coated with superparamagnetic magnetite. Compos. Sci. Technol. 2018, 164, 129-135. [CrossRef]

131. Ralphs, M.; Kong, W.; Wang, R.Y.; Rykaczewski, K. Thermal Conductivity Enhancement of Soft Polymer Composites through Magnetically Induced Percolation and Particle-Particle Contact Engineering. Adv. Mater. Interfaces 2019, 6, 1801857. [CrossRef]

132. Du, C.; Li, M.; Cao, M.; Feng, S.; Guo, H.; Li, B. Enhanced thermal and mechanical properties of polyvinlydene fluoride composites with magnetic oriented carbon nanotube. Carbon 2018, 126, 197-207. [CrossRef]

133. Chung, S.-H.; Kim, H.; Jeong, S.W. Improved thermal conductivity of carbon-based thermal interface materials by high-magneticfield alignment. Carbon 2018, 140, 24-29. [CrossRef] 
134. Zhang, Q.; Li, Z.; Li, X.; Yu, L.; Zhang, Z.; Wu, Z. Zinc ferrite nanoparticle decorated boron nitride nanosheet: Preparation, magnetic field arrangement, and flame retardancy. Chem. Eng. J. 2019, 356, 680-692. [CrossRef]

135. King, L.V. On the Acoustic Radiation Pressure on Spheres. R. Soc. Lond. A Math. Phys. Sci. 1934, 147, 212.

136. Laurell, T.; Petersson, F.; Nilsson, A. Chip integrated strategies for acoustic separation and manipulation of cells and particles. Chem. Soc. Rev. 2007, 36, 492-506. [CrossRef] [PubMed]

137. Bruus, H. Acoustofluidics 7: The acoustic radiation force on small particles. Lab Chip 2012, 12, 1014-1021. [CrossRef]

138. Owens, C.E.; Shields, C.W.; Cruz, D.F.; Charbonneau, P.; López, G.P. Highly parallel acoustic assembly of microparticles into well-ordered colloidal crystallites. Soft Matter 2016, 12, 717-728. [CrossRef]

139. Pain, H.J.; Rankin, P. Introduction to Vibrations and Waves; Wiley: Hoboken, NJ, USA, 2015; ISBN 978-1-118-69838-9.

140. Söllner, K.; Bondy, C. The mechanism of coagulation by ultrasonic waves. Trans. Faraday Soc. 1936, 32, 616-623. [CrossRef]

141. Yosioka, K.; Kawasima, Y. Acoustic Radiation Pressure on a Compressible Spherical. Acustica 1955, 5, 167-173.

142. Gor'kov, L.P. On the Forces Acting on a Small Particle in an Acoustical Field in an Ideal Fluid. Soviet Phys. Doklady $1962,6,773$.

143. Kalb, D.M.; Fencl, F.A.; Woods, T.A.; Swanson, A.; Maestas, G.C.; Juárez, J.J.; Edwards, B.S.; Shreve, A.P.; Graves, S.W. LineFocused Optical Excitation of Parallel Acoustic Focused Sample Streams for High Volumetric and Analytical Rate Flow Cytometry. Anal. Chem. 2017, 89, 9967-9975. [CrossRef]

144. Shi, J.; Ahmed, D.; Mao, X.; Steven Lin, S.-C.; Lawit, A.; Jun Huang, T. Acoustic tweezers: Patterning cells and microparticles using standing surface acoustic waves (SSAW). Lab Chip 2009, 9, 2890-2895. [CrossRef] [PubMed]

145. Kothapalli, S.V.V.N.; Wiklund, M.; Janerot-Sjoberg, B.; Paradossi, G.; Grishenkov, D. Investigation of polymer-shelled microbubble motions in acoustophoresis. Ultrasonics 2016, 70, 275-283. [CrossRef] [PubMed]

146. Cushing, K.W.; Piyasena, M.E.; Carroll, N.J.; Maestas, G.C.; López, B.A.; Edwards, B.S.; Graves, S.W.; López, G.P. Elastomeric Negative Acoustic Contrast Particles for Affinity Capture Assays. Anal. Chem. 2013, 85, 2208-2215. [CrossRef]

147. Saito, M.; Itagaki, K.; Hayashi, K.; Tsubata, K. Composite Materials with Ultrasonically Induced Layer or Lattice Structure. Jpn. J. Appl. Phys. 1999, 38, 3028. [CrossRef]

148. Saito, M.; Imanishi, Y. Host-guest composites containing ultrasonically arranged particles. J. Mater. Sci. 2000, 35, $2373-2377$. [CrossRef]

149. Saito, M.; Daian, T.; Hayashi, K.; Izumida, S.-Y. Fabrication of a polymer composite with periodic structure by the use of ultrasonic waves. J. Appl. Phys. 1998, 83, 3490-3494. [CrossRef]

150. Mitri, F.G.; Garzon, F.H.; Sinha, D.N. Characterization of acoustically engineered polymer nanocomposite metamaterials using x-ray microcomputed tomography. Rev. Sci. Instrum. 2011, 82, 034903. [CrossRef]

151. Melde, K.; Mark, A.G.; Qiu, T.; Fischer, P. Holograms for acoustics. Nature 2016, 537, 518-522. [CrossRef]

152. Zhang, J.; Yang, Y.; Zhu, B.; Li, X.; Jin, J.; Chen, Z.; Chen, Y.; Zhou, Q. Multifocal point beam forming by a single ultrasonic transducer with 3D printed holograms. Appl. Phys. Lett. 2018, 113, 243502. [CrossRef]

153. Melde, K.; Choi, E.; Wu, Z.; Palagi, S.; Qiu, T.; Fischer, P. Acoustic Fabrication via the Assembly and Fusion of Particles. Adv. Mater. 2018, 30. [CrossRef] [PubMed]

154. Collino, R.R.; Ray, T.R.; Fleming, R.C.; Cornell, J.D.; Compton, B.G.; Begley, M.R. Deposition of ordered two-phase materials using microfluidic print nozzles with acoustic focusing. Extreme Mech. Lett. 2016, 8, 96-106. [CrossRef]

155. Xu, F.; Finley, T.D.; Turkaydin, M.; Sung, Y.; Gurkan, U.A.; Yavuz, A.S.; Guldiken, R.O.; Demirci, U. The assembly of cellencapsulating microscale hydrogels using acoustic waves. Biomaterials 2011, 32, 7847-7855. [CrossRef] [PubMed]

156. Dual, J.; Möller, D. Chapter Piezoelectricity and Application to the Excitation of Acoustic Fields for Ultrasonic Particle Manipulation. In Microscale Acoustofluidics; Laurell, T., Lenshof, A., Eds.; Royal Society of Chemistry: Cambridge, UK, 2014; pp. 81-99. ISBN 978-1-84973-671-8.

157. Collino, R.R.; Ray, T.R.; Friedrich, L.M.; Cornell, J.D.; Meinhart, C.D.; Begley, M.R. Scaling relationships for acoustic control of two-phase microstructures during direct-write printing. Mater. Res. Lett. 2018, 6, 191-198. [CrossRef]

158. Whittaker, M.A.; Dauson, E.R.; Parra-Raad, J.; Heard, R.A.; Oppenheim, I.J. Ultrasonic Alignment of Microparticles in Nozzle-like Geometries. In Behavior and Mechanics of Multifunctional Materials and Composites XII; Naguib, H.E., Ed.; Spie-Int Soc Optical Engineering: Bellingham, WA, USA, 2018; Volume 10596. [CrossRef]

159. Friedrich, L.; Collino, R.; Ray, T.; Begley, M. Acoustic control of microstructures during direct ink writing of two-phase materials. Sens. Actuators A Phys. 2017, 268, 213-221. [CrossRef]

160. Lu, L.; Tang, X.; Hu, S.; Pan, Y. Acoustic Field-Assisted Particle Patterning for Smart Polymer Composite Fabrication in Stereolithography. 3D Print. Addit. Manuf. 2018, 5, 151-159. [CrossRef]

161. Greenhall, J.; Raeymaekers, B. 3D Printing Macroscale Engineered Materials Using Ultrasound Directed Self-Assembly and Stereolithography. Adv. Mater. Technol. 2017, 2, 1700122. [CrossRef]

162. Collino, R.R.; Ray, T.R.; Fleming, R.C.; Sasaki, C.H.; Haj-Hariri, H.; Begley, M.R. Acoustic field controlled patterning and assembly of anisotropic particles. Extreme Mech. Lett. 2015, 5, 37-46. [CrossRef]

163. Scholz, M.S.; Drinkwater, B.W.; Llewellyn-Jones, T.M.; Trask, R.S. Counterpropagating wave acoustic particle manipulation device for the effective manufacture of composite materials. IEEE Trans. Ultrason. Ferroelectr. Freq. Control. 2015, 62, 1845-1855. [CrossRef] 
164. Nichols, M.K.; Kumar, R.K.; Bassindale, P.G.; Tian, L.; Barnes, A.C.; Drinkwater, B.W.; Patil, A.J.; Mann, S. Fabrication of Micropatterned Dipeptide Hydrogels by Acoustic Trapping of Stimulus-Responsive Coacervate Droplets. Small 2018, 14, e1800739. [CrossRef]

165. Llewellyn-Jones, T.M.; Drinkwater, B.W.; Trask, R.S. 3D printed components with ultrasonically arranged microscale structure. Smart Mater. Struct. 2016, 25, 02LT01. [CrossRef]

166. Haslam, M.D.; Raeymaekers, B. Aligning carbon nanotubes using bulk acoustic waves to reinforce polymer composites. Compos. Part B Eng. 2014, 60, 91-97. [CrossRef]

167. Doblhoff-Dier, O.; Gaida, T.; Katinger, H.; Burger, W.; Groschl, M.; Benes, E. A Novel Ultrasonic Resonance Field Device for the Retention of Animal Cells. Biotechnol. Prog. 1994, 10, 428-432. [CrossRef] [PubMed]

168. Zhang, J.; Collins, A.; Chen, M.; Knyazev, I.; Gentz, R. High-density perfusion culture of insect cells with a BioSep ultrasonic filter. Biotechnol. Bioeng. 1998, 59, 351-359. [CrossRef]

169. Gherardini, L.; Radel, S.; Sielemann, S.; Doblhoff-Dier, O.; Gröschl, M.; Benes, E.; McLoughlin, A.J. A study of the spatial organisation of microbial cells in a gel matrix subjected to treatment with ultrasound standing waves. Bioseparation 2001, 10, 153-162. [CrossRef] [PubMed]

170. Gherardini, L.; Cousins, C.M.; Hawkes, J.J.; Spengler, J.; Radel, S.; Lawler, H.; Devcic-Kuhar, B.; Gröschl, M.; Coakley, W.T.; McLoughlin, A.J. A new immobilisation method to arrange particles in a gel matrix by ultrasound standing waves. Ultrasound Med. Biol. 2005, 31, 261-272. [CrossRef] [PubMed]

171. Garvin, K.A.; Hocking, D.C.; Dalecki, D. Controlling the Spatial Organization of Cells and Extracellular Matrix Proteins in Engineered Tissues Using Ultrasound Standing Wave Fields. Ultrasound Med. Biol. 2010, 36, 1919-1932. [CrossRef] [PubMed]

172. Mazzoccoli, J.P.; Feke, D.L.; Baskaran, H.; Pintauro, P.N. Development of multilayered cell-hydrogel composites using an acoustic focusing technique. Biotechnol. Prog. 2010, 26, 600-605. [CrossRef] [PubMed]

173. Garvin, K.A.; Dalecki, D.; Hocking, D.C. Vascularization of Three-Dimensional Collagen Hydrogels Using Ultrasound Standing Wave Fields. Ultrasound Med. Biol. 2011, 37, 1853-1864. [CrossRef]

174. Sriphutkiat, Y.; Zhou, Y. Acoustic manipulation of microparticle in a cylindrical tube for 3D printing. Rapid Prototyp. J. 2019, 25, 925-938. [CrossRef]

175. Foresti, D.; Kroll, K.T.; Amissah, R.; Sillani, F.; Homan, K.A.; Poulikakos, D.; Lewis, J.A. Acoustophoretic printing. Sci. Adv. 2018, 4, eaat1659. [CrossRef]

176. Guo, J.; Li, J.L.W.; Chen, Y.; Yeo, L.Y.; Friend, J.R.; Kang, Y. RF-Activated Standing Surface Acoustic Wave for On-Chip Particle Manipulation. IEEE Trans. Microw. Theory Tech. 2014, 62, 1898-1904. [CrossRef]

177. Chen, P.; Güven, S.; Usta, O.B.; Yarmush, M.L.; Demirci, U. Biotunable Acoustic Node Assembly of Organoids. Adv. Healthc. Mater. 2015, 4, 1937-1943. [CrossRef]

178. Serpooshan, V.; Chen, P.; Wu, H.; Lee, S.; Sharma, A.; Hu, D.A.; Venkatraman, S.; Ganesan, A.V.; Usta, O.B.; Yarmush, M.; et al. Bioacoustic-enabled patterning of human iPSC-derived cardiomyocytes into 3D cardiac tissue. Biomaterials 2017, 131, 47-57. [CrossRef] [PubMed]

179. Naseer, S.M.; Manbachi, A.; Samandari, M.; Walch, P.; Gao, Y.; Zhang, Y.S.; Davoudi, F.; Wang, W.; Abrinia, K.; Cooper, J.M.; et al. Surface acoustic waves induced micropatterning of cells in gelatin methacryloyl (GelMA) hydrogels. Biofabrication 2017, 9, 015020. [CrossRef] [PubMed]

180. Vuillermet, G.; Gires, P.-Y.; Casset, F.; Poulain, C. Chladni Patterns in a Liquid at Microscale. Phys. Rev. Lett. 2016, $116,184501$. [CrossRef]

181. Lei, J. Formation of inverse Chladni patterns in liquids at microscale: Roles of acoustic radiation and streaming-induced drag forces. Microfluid. Nanofluid. 2017, 21, 50. [CrossRef]

182. Shabaniverki, S.; Thorud, S.; Juárez, J.J. Protocol for assembling micro- and nanoparticles in a viscous liquid above a vibrating plate. MethodsX 2018, 5, 1156-1165. [CrossRef]

183. Barnkob, R.; Augustsson, P.; Laurell, T.; Bruus, H. Acoustic radiation- and streaming-induced microparticle velocities determined by microparticle image velocimetry in an ultrasound symmetry plane. Phys. Rev. E 2012, 86, 056307. [CrossRef] [PubMed]

184. Halpin, J.C. Stiffness and Expansion Estimates for Oriented Short Fiber Composites. J. Compos. Mater. 1969, 3, 732-734. [CrossRef]

185. Halpin, J.C.; Kardos, J.L. The Halpin-Tsai equations: A review. Polym. Eng. Sci. 1976, 16, 344-352. [CrossRef]

186. Yung, W.K.C.; Wang, J.; Yue, T.M. Modeling Young's Modulus of Polymer-layered Silicate Nanocomposites Using a Modified Halpin-Tsai Micromechanical Model. J. Reinf. Plast. Compos. 2006, 25, 847-861. [CrossRef]

187. Shokrieh, M.M.; Moshrefzadeh-Sani, H. On the constant parameters of Halpin-Tsai equation. Polymer 2016, 106, 14-20. [CrossRef]

188. Song, Y.; Zheng, Q. A Guide for Hydrodynamic Reinforcement Effect in Nanoparticle-filled Polymers. Crit. Rev. Solid State Mater. Sci. 2016, 41, 318-346. [CrossRef]

189. Verberg, R.; De Schepper, I.M.; Cohen, E.G.D. Viscosity of colloidal suspensions. Phys. Rev. E 1997, 55, 3143-3158. [CrossRef]

190. Siacor, F.D.C.; Chen, Q.; Zhao, J.Y.; Han, L.; Valino, A.D.; Taboada, E.B.; Caldona, E.B.; Advincula, R.C. On the additive manufacturing (3D printing) of viscoelastic materials and flow behavior: From composites to food manufacturing. Addit. Manuf. 2021, 45, 102043. [CrossRef]

191. Jefri, M.A.; Zahed, A.H. Elastic and Viscous Effects on Particle Migration in Plane-Poiseuille Flow. J. Rheol. 1989, 33, 691-708. [CrossRef] 
192. Gauthier, F.; Goldsmith, H.L.; Mason, S.G. Particle Motions in Non-Newtonian Media. II. Poiseuille Flow. Trans. Soc. Rheol. 1971, 15, 297-330. [CrossRef]

193. Mirsepassi, A.; Rajaram, B.; Mohraz, A.; Dunn-Rankin, D. Particle chaining and chain dynamics in viscoelastic liquids. J. Non-Newton. Fluid Mech. 2012, 179-180, 1-8. [CrossRef]

194. Won, D.; Kim, C. Alignment and aggregation of spherical particles in viscoelastic fluid under shear flow. J. Non-Newton. Fluid Mech. 2004, 117, 141-146. [CrossRef]

195. Scirocco, R.; Vermant, J.; Mewis, J. Effect of the viscoelasticity of the suspending fluid on structure formation in suspensions. J. Non-Newton. Fluid Mech. 2004, 117, 183-192. [CrossRef]

196. Pasquino, R.; D’Avino, G.; Maffettone, P.L.; Greco, F.; Grizzuti, N. Migration and chaining of noncolloidal spheres suspended in a sheared viscoelastic medium. Experiments and numerical simulations. J. Non-Newton. Fluid Mech. 2014, 203, 1-8. [CrossRef]

197. Tan, A.T.L.; Beroz, J.; Kolle, M.; Hart, A.J. Direct-Write Freeform Colloidal Assembly. Adv. Mater. 2018, 30, 1803620. [CrossRef] [PubMed]

198. Akella, M.; Shabaniverki, S.; Juárez, J.J. Acoustophoretic assembly of millimeter-scale Janus fibers. RSC Adv. 2019, 10, 434-443. [CrossRef]

199. Abramchuk, S.; Kramarenko, E.; Stepanov, G.; Nikitin, L.V.; Filipcsei, G.; Khokhlov, A.R.; Zrínyi, M. Novel highly elastic magnetic materials for dampers and seals: Part I. Preparation and characterization of the elastic materials. Polym. Adv. Technol. 2007, 18, 883-890. [CrossRef]

200. Baxter-Drayton, Y.; Brady, J.F. Brownian Electrorheological Fluids as a Model for Flocculated Dispersions. J. Rheol. 1996, 40, 1027-1056. [CrossRef]

201. Song, Y.; Mason, E.A.; Stratt, R.M. Why does the Carnahan-Starling equation work so well? J. Phys. Chem. 1989, 93, 6916-6919. [CrossRef]

202. Yethiraj, A. Tunable colloids: Control of colloidal phase transitions with tunable interactions. Soft Matter 2007, 3, 1099-1115. [CrossRef]

203. Adriani, P.M.; Gast, A.P. Electric-field-induced aggregation in dilute colloidal suspensions. Faraday Discuss. 1990, 90, 17-29. [CrossRef]

204. Spatafora-Salazar, A.; Lobmeyer, D.; Cunha, L.H.P.; Joshi, K.; Biswal, S.L. Hierarchical assemblies of superparamagnetic colloids in time-varying magnetic fields. Soft Matter 2021, 17, 1120-1155. [CrossRef]

205. Darras, A.; Opsomer, E.; Vandewalle, N.; Lumay, G. Effect of volume fraction on chains of superparamagnetic colloids at equilibrium. Eur. Phys. J. E 2019, 42, 123. [CrossRef] [PubMed]

206. Barnkob, R.; Augustsson, P.; Laurell, T.; Bruus, H. Measuring the local pressure amplitude in microchannel acoustophoresis. Lab Chip 2010, 10, 563-570. [CrossRef] [PubMed]

207. Doinikov, A.A. Acoustic radiation forces: Classical theory and recent advances. In Recent Research Devleopments in Acoustics; Transworld Research Network: Trivandrum, India, 2003; ISBN 8178950839.

208. Apfel, R.E. Acoustically induced square law forces and some speculations about gravitation. Am. J. Phys. 1988, 56, 726-729. [CrossRef]

209. Schneider, F.; Draheim, J.; Kamberger, R.; Wallrabe, U. Process and material properties of polydimethylsiloxane (PDMS) for Optical MEMS. Sens. Actuators A Phys. 2009, 151, 95-99. [CrossRef]

210. Zheng, Z.M.; Wang, B. A prediction model for the effective thermal conductivity of nanofluids considering agglomeration and the radial distribution function of nanoparticles. Acta Mech. Sin. 2018, 34, 507-514. [CrossRef]

211. Hong, H.; Kim, J.U.; Kim, T.-I. Effective Assembly of Nano-Ceramic Materials for High and Anisotropic Thermal Conductivity in a Polymer Composite. Polymers 2017, 9, 413. [CrossRef]

212. Kim, C.-Y.; Dang, T.M.L.; Zhang, Y.; Yang, J.-F.; Wang, B. The alignment of AlN platelets in polymer matrix and its anisotropic thermal properties. J. Mater. 2019, 5, 679-687. [CrossRef]

213. Louis, P.; Gokhale, A.M. Computer simulation of spatial arrangement and connectivity of particles in three-dimensional microstructure: Application to model electrical conductivity of polymer matrix composite. Acta Mater. 1996, 44, 1519-1528. [CrossRef]

214. Jang, S.-H.; Park, Y.-L.; Yin, H. Influence of Coalescence on the Anisotropic Mechanical and Electrical Properties of Nickel Powder/Polydimethylsiloxane Composites. Materials 2016, 9, 239. [CrossRef]

215. Yakovenko, O.; Matzui, L.; Danylova, G.; Zadorozhnii, V.; Vovchenko, L.; Perets, Y.; Lazarenko, O. Electrical Properties of Composite Materials with Electric Field-Assisted Alignment of Nanocarbon Fillers. Nanoscale Res. Lett. 2017, 12, 471. [CrossRef]

216. Yethiraj, A.; van Blaaderen, A. A Colloidal Model System with an Interaction Tunable from Hard Sphere to Soft and Dipolar. Nature 2003, 421, 513-517. [CrossRef] [PubMed]

217. Swan, J.W.; Bauer, J.L.; Liu, Y.; Furst, E.M. Directed colloidal self-assembly in toggled magnetic fields. Soft Matter 2014, 10, 1102-1109. [CrossRef]

218. Chaudhary, K.; Juárez, J.J.; Chen, Q.; Granick, S.; Lewis, J.A. Reconfigurable assemblies of Janus rods in AC electric fields. Soft Matter 2014, 10, 1320-1324. [CrossRef] [PubMed]

219. Singh, J.P.; Lele, P.P.; Nettesheim, F.; Wagner, N.J.; Furst, E.M. One- and Two-Dimensional Assembly of Colloidal Ellipsoids in Ac Electric Fields. Phys. Rev. E 2009, 79, 050401. [CrossRef] 
220. Demirörs, A.F.; Johnson, P.M.; van Kats, C.M.; van Blaaderen, A.; Imhof, A. Directed Self-Assembly of Colloidal Dumbbells with an Electric Field. Langmuir 2010, 26, 14466-14471. [CrossRef] [PubMed]

221. Raffiee, A.H.; Ardekani, A.M.; Dabiri, S. Numerical investigation of elasto-inertial particle focusing patterns in viscoelastic microfluidic devices. J. Non-Newton. Fluid Mech. 2019, 272, 104166. [CrossRef]

222. Del Giudice, F.; Sathish, S.; D'Avino, G.; Shen, A.Q. “From the Edge to the Center”: Viscoelastic Migration of Particles and Cells in a Strongly Shear-Thinning Liquid Flowing in a Microchannel. Anal. Chem. 2017, 89, 13146-13159. [CrossRef] [PubMed]

223. D'Avino, G.; Greco, F.; Maffettone, P.L. Particle Migration due to Viscoelasticity of the Suspending Liquid and Its Relevance in Microfluidic Devices. Annu. Rev. Fluid Mech. 2017, 49, 341-360. [CrossRef]

224. Edwards, T.D.; Bevan, M.A. Controlling Colloidal Particles with Electric Fields. Langmuir 2014, 30, 10793-10803. [CrossRef]

225. Juárez, J.J.; Bevan, M.A. Feedback Controlled Colloidal Self-Assembly. Adv. Funct. Mater. 2012, 22, 3833-3839. [CrossRef]

226. Juárez, J.J.; Mathai, P.P.; Liddle, J.A.; Bevan, M.A. Multiple electrokinetic actuators for feedback control of colloidal crystal size. Lab Chip 2012, 12, 4063. [CrossRef]

227. Gao, Y.; Lakerveld, R. Gain scheduling PID control for directed self-assembly of colloidal particles in microfluidic devices. AIChE J. 2019, 65, e16582. [CrossRef]

228. Gao, Y.; Lakerveld, R. Feedback control for shaping density distributions of colloidal particles in microfluidic devices. Lab Chip 2019, 19, 2168-2177. [CrossRef]

229. Tang, X.; Rupp, B.; Yang, Y.; Edwards, T.D.; Grover, M.A.; Bevan, M.A. Optimal Feedback Controlled Assembly of Perfect Crystals. ACS Nano 2016, 10, 6791-6798. [CrossRef]

230. Gao, Y.; Nyande, B.W.; Lakerveld, R. Open-loop control of directed self-assembly of colloidal particles in a microfluidic device. Comput. Chem. Eng. 2020, 139, 106837. [CrossRef]

231. Tang, X.; Zhang, J.; Bevan, M.A.; Grover, M.A. A comparison of open-loop and closed-loop strategies in colloidal self-assembly. J. Process. Control 2017, 60, 141-151. [CrossRef] 